\title{
Specificity of transaminase activities in the prediction of drug-induced hepatotoxicity
}

\author{
Akio Kobayashi, Yusuke Suzuki and Shoichiro Sugai \\ Toxicology Research Lab., Central Pharmaceutical Research Institute, JAPAN TOBACCO INC., \\ 1-13-2 Fukuura, Kanazawa, Yokohama, Kanagawa 236-0004, Japan
}

(Received April 19, 2020; Accepted June 4, 2020)

\begin{abstract}
The activities of the transaminases (aminotransferases) alanine aminotransferase and aspartate aminotransferase in the blood (serum or plasma) are widely used as sensitive markers of possible tissue damage and, in particular for liver toxicity. On the other hand, an increase in transaminase activities is not always accompanied by findings suggestive of hepatotoxicity. Transaminases are some of the key enzymes in the gluconeogenesis and glycolysis pathways and exist in many organs and tissues which have high activities of the gluconeogenesis and glycolysis. The activities of transaminases are altered not only in the liver but also in other organs by modification of gluconeogenesis by nutritional or hormonal factors and this phenomenon leads to alteration of transaminase activity in the blood. Drugs, which are considered to directly or secondarily modify gluconeogenesis through lowering blood glucose levels or activating lipid metabolism, such as $\alpha$-glucosidase inhibitors and fibrates, slightly increase transaminase activities in the blood but there is little evidence that the phenomenon is related to drug-induced liver injury (DILI). This type of elevations can be called pharmacology-related elevation. The pharmacology-related elevation of transaminase activities sometimes makes it difficult to assess precisely the potential hepatotoxicity of new investigational drugs. Considering the characteristic of transaminases, concomitant use of new biomarkers more specific to hepatic injury is needed in the assessment of DILI both in non-clinical and clinical studies. In this review, we will discuss the specificity of transaminases to DILI and future perspectives for transaminases in the estimation of risk of DILI.
\end{abstract}

Key words: Alanine aminotransferase, Aspartate aminotransferase, Glucose metabolism, Lipid metabolism, Drug-induced liver injury, Biomarker

\section{INTRODUCTION}

Transaminases (aminotransferases), alanine aminotransferase (ALT) and aspartate aminotransferase (AST), have been widely used as sensitive markers of possible tissue damage, particularly liver toxicity, for many years both in non-clinical toxicology studies and clinical trials (Ramaiah, 2007). Transaminase activity in the blood (serum or plasma) is increased especially in hepatocellular damage induced by drugs or diseases.

In the case of drug-induced liver injury (DILI), blood transaminase levels increase markedly, up to 10- to 100fold, as a consequence of the release of hepatocellular enzyme proteins from the damaged tissue into the circulation. DILI is becoming a significant public health issue because of its potential impact, not only on patients but also on the development of new drugs. DILI events are also the main cause of regulatory action pertaining to drugs, including denial of marketing approval, restrictions with respect to clinical indications and withdrawal from the marketplace (Lee, 2003; Smith and Schmid, 2006). Therefore, it is very important for the risk management of new drugs that DILI or suspected DILI is appropriately evaluated using hepatic function tests, including blood transaminase levels.

On the other hand, transaminase levels are sometimes increased without being associated with alteration of other hepatic function tests, including blood alkaline phosphatase (ALP), lactate dehydrogenase (LDH), total bilirubin (T-BIL), albumin and blood coagulation parameters, or any obvious histopathological findings suggestive of hepatotoxicity in non-clinical toxicology studies. Even

Correspondence: Akio Kobayashi (E-mail: akio.kobayashi@jt.com) 
A. Kobayashi et al.

in clinical trials, we sometimes encounter a phenomenon in which blood transaminase activity is slightly increased without alteration of other hepatic function tests or any symptom and the elevation may return to the basal level despite continuation of dosing of drugs.

Transaminases are widely distributed in organs and tissues other than the liver and it is known that the activity of transaminase in the blood is increased not only in druginduced-hepatotoxicity but also in alteration of nutritional or hormonal conditions (Kobayashi et al., 2011; Horio et al., 1988a, 1988b; Aggerbeck et al., 1993; Barouki et al., 1989). This is because transaminases are some of the key enzymes in gluconeogenesis and glycolysis pathways which are affected by alteration of the nutritional or hormonal condition. Therefore, it is very important to understand the function, distribution and isozymes with their intracellular localization of transaminases. Analyses of the relationship between the elevation of blood transaminase levels and nutritional or hormonal conditions of animals or humans are necessary, when blood transaminase activity is increased slightly without alteration of other liver function tests in non-clinical toxicity studies and clinical trials of drug candidates. Mild and transient elevations of transaminases are sometimes related to the pharmacological action of drugs which modify glucose/ lipid metabolism and this type of elevation can be called pharmacology-related elevation of transaminases. Profiling and investigation of the mechanism of the mild and isolated elevations of transaminases will give insight into differentiation between DILI-related elevations and pharmacology-related elevations of transaminases.

In this review, we summarize the distribution of transaminases in the body, their function in the cell and factors affecting the activity of transaminases in the blood and organs and discuss the mechanisms and toxicological significance in the case of elevation of transaminase in the blood without any obvious evidence of drug-induced hepatotoxicity in non-clinical toxicology studies and clinical trials. Based on these, we will discuss the specificity of transaminases to DILI and future perspectives for transaminases in the estimation of the risk of DILI. As points to note, the activities of transaminases are measured using serum or plasma samples collected from animals and humans; however, serum or plasma transaminase activities are shown simply as blood transaminase activities in this review unless it is necessary to distinguish the use of the two words, serum or plasma.

\section{HISTORY OF MEASUREMENTS OF BLOOD TRANSAMINASE ACTIVITY AND ITS TOXICOLOGICAL SIGNIFICANCE}

Transaminase activity in the blood was originally used as a marker for acute myocardial infarction (Agress et al., 1955; Karmen, 1955) and then has been used as a marker for drug-induced hepatotoxicity for more than 50 years in non-clinical toxicology studies and clinical studies. Drug-induced hepatotoxicity is classified into several classes, including hepatocellular type toxicity, hepatobiliary toxicity and their mixed type toxicity, and transaminase activity is useful to detect especially hepatocellular-type hepatotoxicity (marked hepatocyte cell lysis) (Ramaiah, 2007). Despite the usefulness of transaminases as a marker for hepatotoxicity, the routine use of transaminase activity in clinical chemistry sometimes leads to misunderstanding that elevation of transaminase activity in the blood is a marker which is very specific to hepatocellular-type hepatotoxicity.

Transaminase activities are increased in the blood not only in the case of hepatotoxicity but also in other organ toxicity, including myotoxicity and myocardial toxicity, and hemolysis. In addition, toxicologists or clinicians sometimes encounter the case where elevations of transaminases are not associated with any findings suggestive of organ toxicity, including hepatotoxicity. In such a case, it is difficult to discuss the toxicological significance of the elevations of transaminases, including the risk estimation of DILI (Balfour et al., 1990; Blane, 1987; Gould and Scott, 2005; Kodama et al., 2008).

Misinterpretation of the elevations of transaminases has a risk to draw inappropriate diagnosis or risk estimation when blood transaminases are elevated without any obvious findings suggestive of organ toxicity in non-clinical toxicity studies of drug candidates (Senior, 2006). More understanding the function of transaminases in the cell, distribution of transaminases in organs or tissues and hormonal or nutritional aspects of transaminase elevations will help to avoid misinterpretation and lead to more precise estimation of risk of DILI (Fig. 1).

\section{FUNCTION OF TRANSAMINASES AND GLUCOSE HOMEOSTASIS}

Transaminases have important functions in the glucose homeostasis. Glucose is an essential substrate of mammalian cells and glucose homeostasis is maintained by glucagon and insulin, both of which regulate glucose, protein (amino acids) and fatty acid metabolism in the body. ALT and AST are two of the key enzymes involved in 
Specificity of transaminase activities in drug-induced hepatotoxicity

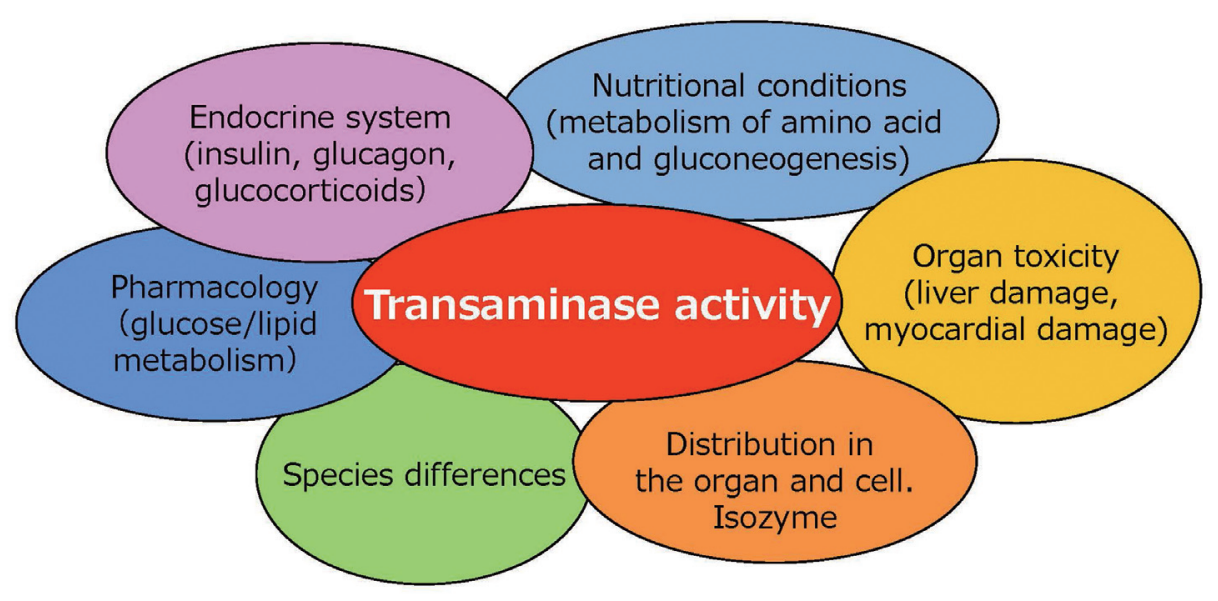

Fig. 1. Factors affecting blood transaminase activity.

the amino acid/glucose metabolism pathways and play an important role in amino acid metabolism in the muscle and gluconeogenesis in various organs/tissues, including the liver, kidney and small intestine (DeRosa and Swick, 1975; Wu, 1998; Kobayashi et al., 2010).

ALT catalyzes the transfer of an amino group from L-alanine to $\alpha$-ketoglutarate, the products of this reversible transamination reaction being pyruvate and L-glutamate, and plays an important role, as an enzyme involved in gluconeogenesis in the liver and glycolysis in the muscle, in the transport of glucose and alanine between the liver and muscle.

AST catalyzes the interconversion of aspartate and $\alpha$-ketoglutarate to oxaloacetate and glutamate and plays an important role in the synthesis of phosphoenolpyruvic acid (PEP), which is an intermediate in the production of glucose and alanine.

In order to facilitate understanding of the functions of transaminases in glucose/amino acid metabolism, the transfer of glucose and alanine between the liver and muscle and the participation of transaminases in glucose/amino acid metabolism under fasting condition are shown in Fig. 2. In the muscle and certain other tissues, ALT degrades amino acids for fuel and amino groups are collected from glutamate by transamination. ALT transfers the alpha-amino group from glutamate to pyruvate to form alanine, which is a major amino acid in the blood during fasting. Alanine is taken up by the liver for generating glucose from pyruvate in a reverse ALT reaction, constituting the so-called alanine-glucose cycle (Dhahbi et al., 1999; Felig, 1973). Under gluconeogenic conditions, AST transports oxaloacetate from mitochondria to the cytoplasm, leading to the generation of PEP from oxaloacetate via the activation of phosphoenolpyruvate carboxykinase (PEPCK) (Horio et al., 1988b).

In gluconeogenesis, there is another metabolic pathway, referred to as the Cori cycle, in which lactate produced by anaerobic glycolysis in the muscles moves to the liver and is converted to glucose, which then returns to the muscles and is cyclically metabolized back to lactate. Gluconeogenesis via the Cori cycle is important under fasting conditions or in heavy physical exercise and transaminases also play an important role in this cycle (DeRosa and Swick, 1975).

Fatty acid metabolism also links closely to gluconeogenesis. When fatty acid oxidation is accelerated, the acceleration is also considered to lead to an increase in the synthesis of enzymes involved in the gluconeogenesis pathway, including AST and ALT (Lam et al., 2003). This is because acetyl CoA produced by fatty acid oxidation inhibits hepatic pyruvate dehydrogenase (PDH) activity and accelerates the production of oxaloacetate from pyruvate via activation of pyruvate carboxylase (PC), leading to glucose production from alanine (Fig. 3). The activation of PC finally leads to activation of other enzymes involved in the gluconeogenesis pathway, including ALT and AST (Lam et al., 2003; Kobayashi et al., 2011).

From these functions of transaminases, one can understand that transaminase activities in the organ/tissue alter due to alterations of the body condition which affects the metabolism of glucose, protein and lipids in humans and animals. 
A. Kobayashi et al.

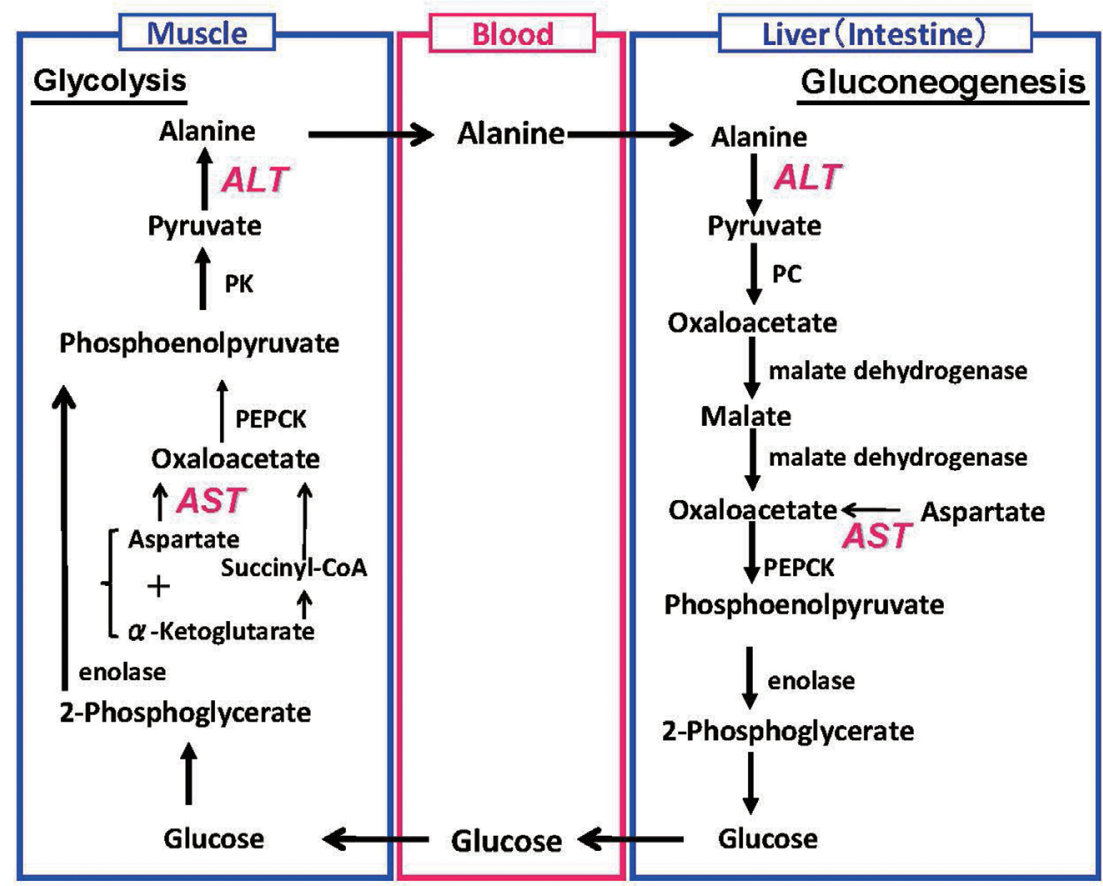

Fig. 2. The physiological role of AST and ALT in mammalian species under fasting condition.

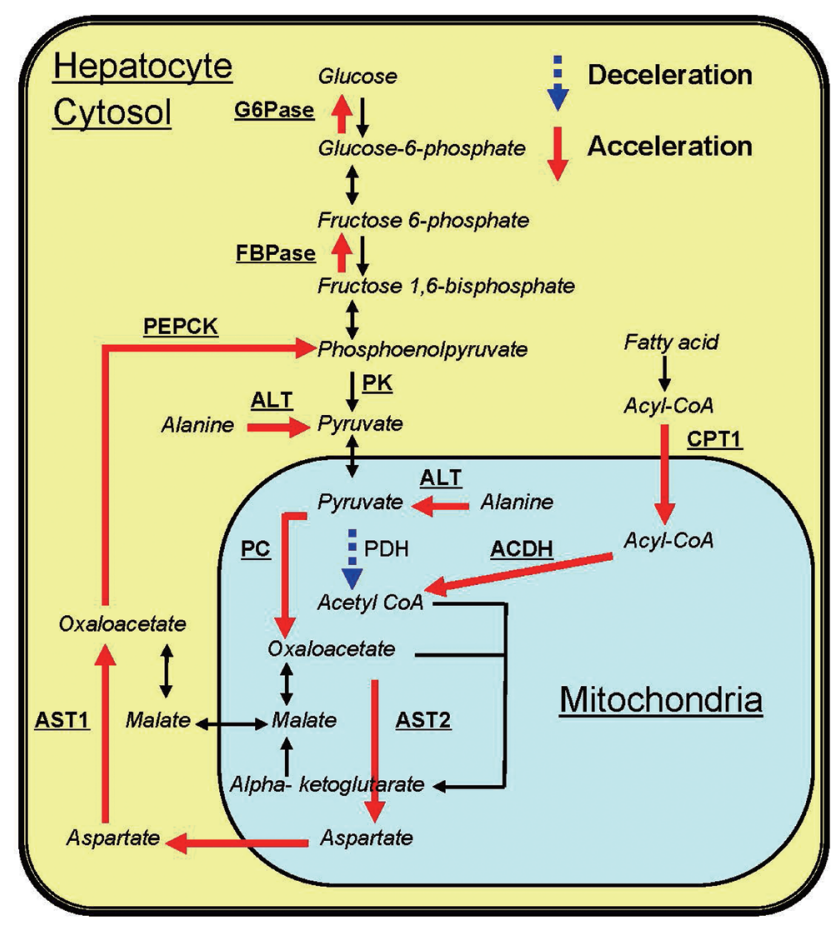

Fig. 3. The pathways of amino acid/glucose/ fatty acid metabolism in the spaced-fed rat hepatocyte. Red arrow shows acceleration, Blue arrow shows deceleration (Kobayashi et al., 2011). 
Specificity of transaminase activities in drug-induced hepatotoxicity

Table 1. Distribution of transaminases in the organs/tissues in animals and humans.

\begin{tabular}{|c|c|c|c|c|c|c|c|c|}
\hline \multirow{3}{*}{ Species } & \multicolumn{8}{|c|}{ Activity relative to activity in the liver (\%) } \\
\hline & \multicolumn{2}{|c|}{ Rat } & \multicolumn{2}{|c|}{ Dog } & \multicolumn{2}{|c|}{ Monkey } & \multicolumn{2}{|c|}{ Human } \\
\hline & ALT & AST & ALT & AST & ALT & AST & ALT & AST \\
\hline Liver & 100 & 100 & 100 & 100 & 100 & 100 & 100 & 100 \\
\hline Kidney & $12-22$ & $52-94$ & $9-24$ & $30-80$ & $0-40$ & $0-62$ & 43 & 64 \\
\hline Muscle & $13-48$ & $69-91$ & $6-7$ & $71-87$ & $28-36$ & $56-68$ & 11 & 70 \\
\hline Heart & $6-40$ & 190 & $20-30$ & $126-261$ & $74-80$ & $154-185$ & $16-35$ & $110-270$ \\
\hline Intestine & $65-73$ & $7-25$ & $0.4-2$ & $10-30$ & $8-15$ & 9-29 & 2 & 4 \\
\hline Brain & 12 & 105 & $2-6$ & $24-90$ & $0-12$ & $0-47$ & NA & NA \\
\hline
\end{tabular}

NA: Not available

Activity relative to the activity in the liver was calculated based on our data and data from literatures for enzyme activity in each tissue (activity per g tissue)

(Remesar et al., 1980; Remesar and Alemany, 1980; Palou et al., 1980; Cornelius et al., 1959; Clampitt and Hart, 1978; Keller, 1981; Kobayashi et al., 2010).

\section{ISOZYMES OF TRANSAMINASES AND THEIR INTRACELLULAR DISTRIBUTION}

ALT exists in the cytosol and mitochondrial fractions in animal and human tissues as two isozymes, possibly corresponding to ALT1 and ALT2, respectively, and the gene for these isozymes (GPT1 and GPT2, respectively) is mainly expressed in the liver (Jadaho et al., 2004; Yang et al., 2009). In rats, ALT1 gene is mainly expressed in the intestine, liver, fat tissues, colon, muscle and heart, whereas the ALT2 gene is mainly expressed in the liver, muscle, brain and white adipose tissue (Yang et al., 2009). Hepatic ALT activity might be a sum of hepatic ALT1 and ALT2 activities, because serum ALT activity is positively correlated with both ALT1 and ALT2 protein levels when hepatotoxicity was induced by chemicals.

AST also exists in the cytosol and mitochondrial fractions of animal and human tissues as two isozymes (Horio et al., 1988b; Kobayashi et al., 2011). AST1 and AST2 are cytosol- and mitochondria-type isozymes, respectively, and hepatic AST activity can be shown as a sum of the AST1 and AST2 activities (Leung and Henderson, 1981).

Both cytosolic and mitochondrial transaminases are considered to contribute to glucose formation from alanine or lactate in the liver although the contribution rates of the cytosolic and mitochondrial enzymes are considered to be different between different animal species (DeRosa and Swick, 1975).

Measurement methods for plasma mitochondriatype ALT or cytosol-type ALT have not been established (Rafter et al., 2012). Differences in the physicochemical properties between mitochondrial and cytosolic AST have been reported and the measurement methods of plasma mitochondria-type AST activity have been established
(Watazu et al., 1993).

\section{DISTRIBUTION OF ALT AND AST IN ORGANS AND TISSUES}

Although it is generally thought that transaminase elevations in the blood are due to cell damage with plasma membrane disruption, other mechanisms can be involved in the elevations.

In any case, in order to discuss the origin of transaminase increased in the blood, it is important to understand the distribution of transaminases in the body. Transaminases distribute with high activity not only in the liver but also in other organs and tissues, including the kidney, skeletal muscle, cardiac muscle, digestive tract and brain in animals and humans (Remesar et al., 1980; Palou et al., 1980; Cornelius et al., 1959; Clampitt and Hart, 1978; Keller, 1981).

In any species, including humans, ALT activity (activity per g tissue) is higher in the liver than in other organs and tissues (Table 1). AST activity (activity per g tissue) in the muscle and heart, on the other hand, is comparable to or higher than that in the liver in animals and humans. In the intestine, transaminase activity is relatively high when compared with activity in the liver in rats, while the activity is relatively low in the human intestine. When the AST activity relative to ALT activity (AST/ALT ratio) is compared between the organs/tissues in animals and humans (Table 2), the AST/ALT ratio tends to be higher especially in the skeletal muscle, heart and brain, all of which have high energy consumption and utilize glucose as an energy source via glycolysis. High AST activity in these organs may be explained as discussed by McGill (2016). Namely, the most important physiological func- 
A. Kobayashi et al.

Table 2. AST/ALT ratio in the organs/tissues in animals and humans.

\begin{tabular}{|c|c|c|c|c|}
\hline \multirow{2}{*}{ Species } & \multicolumn{4}{|c|}{ AST/ALT ratio } \\
\hline & Rat & Dog & Monkey & Human \\
\hline Liver & $3.0-4.5$ & $1.1-1.7$ & $0.7-1.7$ & $1.5-2.3$ \\
\hline Kidney & 18.7 & $3.8-8.3$ & $2.1-2.7$ & 4.8 \\
\hline Muscle & 11.8 & $12.4-26.0$ & $1.7-2.1$ & 21 \\
\hline Heart & 6.2 & 7.7-9.9 & $1.5-3.2$ & $10-22$ \\
\hline Intestine & $0.4-1.5$ & $12.0-31.3$ & $1.3-3.0$ & 4.4 \\
\hline Brain & 38.3 & $10.2-16.6$ & 5.3 & NA \\
\hline
\end{tabular}

NA: Not available

AST/ALT ratio was calculated based on our data and data from literatures for enzyme activity in each tissue (activity per g tissue) (Remesar et al., 1980; Remesar and Alemany, 1980; Palou et al., 1980; Cornelius et al., 1959; Clampitt and Hart, 1978; Keller, 1981).

tion of AST may be maintenance of the NAD+/NADH ratio within cells. AST is a critical partner in the malateaspartate shuttle, which oxidizes NADH in the cytosol and reduces NAD + in the mitochondrial matrix to facilitate glycolysis and electron transport, respectively.

On the other hand, the liver, kidney and intestine, all of which have high gluconeogenesis capacity, tend to have lower AST/ALT ratios when compared with the organs which have high glycolysis capacity (Table 2). Although this is the usual pattern across animal species, there are several exceptions. For instance, the AST/ALT ratio is much higher in the intestine, where ALT activity is hardly detected, in dogs and in the kidney in rats when compared to other animal species and humans (Remesar et al., 1980; Palou et al., 1980; Cornelius et al., 1959; Clampitt and Hart, 1978; Keller, 1981). High ALT activity in the gluconeogenic organs may be explained as proposed by McCommis et al. (2015) that the mitochondrial isoform of ALT is particularly important in gluconeogenesis in some cases.

The basal levels of transaminases in the blood can be explained by the release of cellular enzyme proteins into the circulation during normal cell turnover (Schmidt and Schmidt, 1989). Although the main source of the enzyme is considered to be the liver (Schmidt and Schmidt, 1989), other sources should be taken into consideration based on the enzyme activity and the size of the organ/tissues when transaminase activity is increased in the blood. In other words, transaminase activity in the blood is considered to be the sum of the activities of transaminase released from different transaminase-rich tissues into the circulation during normal cell turnover.

In order to investigate the contribution of ALT released from the organs in explaining the alterations in ALT activities in the blood, Kobayashi et al. (2010) introduced body weight-adjusted ALT (BWA-ALT) activity per whole tissue, which was calculated using the fol- lowing formula: BWA-ALT activity per whole tissue $(\mathrm{IU} /$ tissue $/ \mathrm{g}$ body weight $)=($ activity per $\mathrm{g}$ tissue $\times$ tissue weight $(\mathrm{g})) /$ body weight $(\mathrm{g})$ in rats. The calculation was conducted in order to eliminate bias due to fluctuation in body weights in comparison of the enzyme activity per whole tissue with the enzyme activity in the circulation, the volume of which correlates to the body weight. Based on the calculation, the small intestine, one of the gluconeogenic organs (Croset et al., 2001; Watford, 2005; Martin et al., 2007), has high ALT activity as well as the liver in rats (Kobayashi et al., 2010) as previously reported (Palou et al., 1980). On the other hand, in the kidney, which is also a gluconeogenic organ, ALT activity per whole organ is less than $3 \%$ of that of per whole liver and the contribution of ALT released from the kidney into the circulation seemed to be negligible (Clampitt and Hart, 1978; Palou et al., 1980; Kobayashi et al., 2010).

The information on the differences in distribution of transaminases and AST/ALT ratio among organs and tissues can give an insight to toxicologists in preparing the discussion for the toxicological significance of elevation of transaminase activity in the blood without any alteration of other liver function tests or histopathological findings suggestive of hepatotoxicity in toxicology studies for drug candidates. Regarding the distribution of transaminase in the organs/tissues, it is worthy of notice that the enzyme activity is especially high in the organs which have high metabolic activity of glucose, lipids and proteins. Transaminases are involved in glucose/amino acid metabolism pathway in the cells as mentioned above. Therefore, if this pathway is accelerated by treatment with drugs, transaminase activity in the cells will increase. As a consequence, transaminase activity will be increased in the blood through mechanisms that are different from that of organ toxicity. 
Specificity of transaminase activities in drug-induced hepatotoxicity

\section{FACTORS AFFECTING TRANSAMINASE ACTIVITIES IN ORGANS AND BLOOD}

\section{Nutritional and hormonal factors}

The activities of the enzymes involved in gluconeogenesis, including PC and PEPCK, are known to be increased in the liver by starvation or spaced feeding in rats (Chakrabarty and Leveille, 1968; Palou et al., 1980; Lam et al., 2003; Habold et al., 2005; Kobayashi et al., 2011). The activities of transaminases in the cell are considered to be connected with activities of other gluconeogenesis-related enzymes involved in the amino acid/ glucose/lipid metabolism pathways and must be altered as well as for other gluconeogenesis-related enzymes if nutritional fluctuation, which leads to acceleration or deceleration of gluconeogenesis, occurs.

The levels of several hormones are closely linked to the feeding status and the fluctuations of these hormones lead to alteration of the gluconeogenesis-related enzyme levels in the tissues. These hormones include insulin, glucocorticoid and glucagon. Insulin suppresses gene expression of the gluconeogenesis-related enzymes and hypoinsulinemia leads to acceleration of gluconeogenesis. Glucocorticoid induces synthesis of gluconeogenesis-related enzyme proteins, leading to acceleration of gluconeogenesis in the liver and enhancement of lipolysis and protein degradation in the adipose tissue and muscle and supplies gluconeogenesis precursors, including amino acids and glycerol, to the liver. Glucagon enhances glycogenolysis and gluconeogenesis in the liver under fasting conditions. Therefore, the fluctuations in these hormones must lead to alteration of the transaminase levels in the tissues.

In humans, fluctuations in serum transaminase levels have been noted during acute weight loss with fasting or semistarvation and these abnormalities subside promptly when a normal dietary intake is resumed (Verdy, 1966; Drenick et al., 1970). It has been reported that men on high-fat diets ( $60 \%$ of caloric intake) developed serum ALT levels greater than normal while serum LDH, AST and ALP levels were normal and significant correlations between serum triglycerides and ALT levels were found in several subjects (Katchman and Zipf, 1970). The finding of this study indicates that serum ALT levels are of fundamental significance along with blood triglycerides in the evaluation of fatty livers.

In animals, it has been reported that transaminase levels in the blood or organs/tissues change with nutritional or hormonal fluctuation (Horio et al., 1988a; Hoffmann et al., 1989; Kobayashi et al., 2010, 2011; Herzfeld and Greengard, 1971; Chen et al., 1993; Jean et al., 2001;
Ramesh and Pugalendi, 2006; Rosen et al., 1959; Hagopian et al., 2003). Low levels of insulin and high levels of glucocorticoid and glucagon lead to elevations of transaminases in the blood and tissues (Ramesh and Pugalendi, 2006; Rosen et al., 1959; Hoffmann et al., 1989). Caloric restriction is a good model to understand relationships between acceleration of gluconeogenesis, fatty acid metabolism and induction of hepatic transaminases, because the alanine-glucose cycle is enhanced (Dhahbi et al., 1999; Felig, 1973) and fatty acid synthesis and whole body fat oxidation rates are also enhanced in caloric restriction (Bruss et al., 2010). The activity of transaminases is increased in the liver when gluconeogenesis and protein catabolism are accelerated in mice and rats after caloric restriction (Hagopian et al., 2003; Kobayashi et al., 2011). It has been also reported that moderate dietary restriction and feeding a high protein diet caused an elevations of transaminase levels in the blood and tissues in rats (Chen et al., 1993; Jean et al., 2001). We investigated the effects of restricted feeding on plasma ALT levels in rabbits and the ALT levels were increased in restricted-fed rabbits when compared with ad libitum-fed rabbits (Fig. 4). The magnitude of the increase in plasma ALT levels was correlated with the degree of diet restriction, however, the increase was within 2 or 3 folds of baselines and was not enhanced with prolongation of the restricted-fed period.

The elevation of transaminase levels in organs and tissues caused by nutritional or hormonal fluctuation is related to increased synthesis of the enzyme proteins (i.e., increased gene expression) based on the results of several in vitro and in vivo studies. The expression of the rat cytosolic AST gene in the hepatoma cell line Fao is modified by glucocorticoids, insulin and cAMP (Aggerbeck et al., 1993; Barouki et al., 1989). It has been reported that cytosolic AST activity in the liver was elevated in rats fed high-protein diet or glucagon injection during starvation and the elevation was associated with an increase in the mRNA of AST in the cytoplasm (Horio et al., 1988a, 1988b). The elevation of cytosolic AST activities and mRNA of AST in the cytoplasm was also noted after treatment with glucagon in cultured rat hepatocytes (Horio et al., 1988c). It has been also reported that the mRNA levels of gluconeogenic enzymes, including PC, PEPCK, fructose-1,6-bisphosphatase (FBPase) and glucose-6-phosphatase (G6Pase), enzymes involved in fatty acid oxidation, including carnitine palmitoyltransferase (CPT1) and Acyl-CoA dehydrogenase (ACDH), and ALT1, ALT2, AST1 and AST2 in the liver were increased in spaced-fed (SF) rats that were fed in a specified time zone (Kobayashi et al., 2011). From these findings, the 
A. Kobayashi et al.

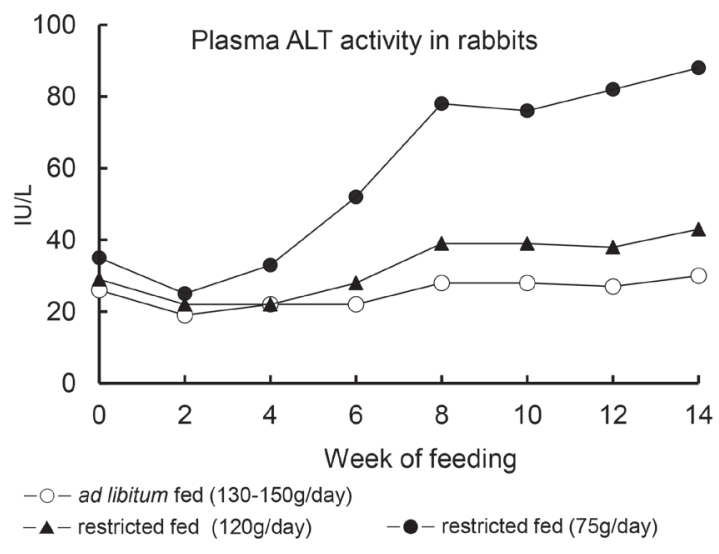

Fig. 4. The effects of restricted feeding on plasma ALT levels in rabbits.

gene expression of enzymes involved in gluconeogenesis and fatty acid oxidation is considered to be regulated by the nutritional status such that alteration of the nutritional state affects this regulation.

The expression of the hepatic clock genes, including period circadian protein homolog 1 (Per1) and brain and muscle aryl hydrocarbon receptor nuclear translocator-like 1 (Bmal1), is well known to tick with a circadian rhythm, however, hepatic Per1 and Bmal1 genes are reset by alteration of the feeding schedule (Rutter et al., 2001; Stokkan et al., 2001; Satoh et al., 2006; Wu et al., 2008). The two hepatic clock genes regulate gene expression of the enzymes related to gluconeogenesis and fatty acid oxidation, including G6Pase and CPT1, and are considered to contribute to homeostasis by driving a daily rhythm of hepatic glucose export that counterbalances the daily cycle of glucose ingestion resulting from the fasting-feeding cycle (Lamia et al., 2008). Ad libitum fed rats consume larger amounts of food in the dark phase when the rats are active as compared with those in the light phase. Hepatic Per1 mRNA levels are consistently low in the light phase and increase in the dark phase and, in contrast to the circadian rhythm of hepatic Per1, hepatic Bmal1 mRNA levels are high in the light phase and decrease in the dark phase under ad libitum feeding conditions (Peirson et al., 2006; Wu et al., 2008). In the daytime SF rats with dietary restriction, the hepatic clock genes are reset (Wu et al., 2008) and the daytime SF animals with dietary restriction are well known to show some characteristic adaptive changes in energy metabolism, glucose synthesis and fatty acid oxidation associated with the shift of the animal's circadian rhythms (Báez-Ruiz et al., 2005; Leveille and Chakrabarty, 1968; Satoh et al., 2006; Wu et al., 2008). Kobayashi et al. (2011) investigated the relationships between hepatic transaminase activities with gene expression of the transaminase isozymes and the state of the hepatic amino acid/glucose/fatty acid metabolism in association with the hepatic clock gene expressions in ad libitum-fed (ALF) and daytime SF rats

In the daytime SF rats, plasma glucose levels were maintained (Kobayashi et al., 2011) and this was considered to be due to hepatic gluconeogenesis using alanine supplied by the muscles after adaptation to the spaced feeding condition (Garber et al., 1976; Leveille and Chakrabarty, 1968). Expression of hepatic clock gene, Per1 and Bmal1, was altered in the SF rats as reported previously.

Acceleration of hepatic gluconeogenesis, as indicated by increased hepatic mRNA levels of PC, PEPCK, FBPase and G6Pase, and fatty acid oxidation, as indicated by increased hepatic mRNA levels of CPT1 and $\mathrm{ACDH}$, was noted in the SF rats. Hepatic transaminase activities in the SF rats were higher than those in the ALF rats. The increase in hepatic transaminase activity in the SF rats was associated with increases in the gene expression of transaminase isozymes, ALT1, ALT2, AST1 and AST2, indicating that the alterations of hepatic transaminase activities were due to increases in the synthesis of hepatic ALT and AST proteins. From these observations, the gene expression of hepatic transaminases is also regulated by hepatic clock gene expression as well as other enzymes involved in gluconeogenesis and fatty acid oxidation. Although investigations on the elevations of transaminases in the organs after caloric restriction have been conducted mainly for the liver, transaminase, as ubiquitous enzymes, are widely distributed in many tissues, indicating that alterations in transaminase activities in the different transaminase-rich tissues lead to changes in transaminase activities in the blood (Clampitt and Hart, 1978; Palou et al., 1980).

In order to verify the nutritional aspect of alterations of the plasma and tissue transaminase activities, Kobayashi et al. (2010) compared the transaminase activities between plasma and organs/tissues using SF rats and ad libitum fed rats. In this study, plasma ALT activity increased in the late phase of restricted feeding and this increase was considered to be related to increases in ALT activities in the liver. Plasma AST activities did not change in the restricted-fed rats throughout the experiment period. On the other hand, a decrease in plasma ALT activities was noted in the early phase of food restriction in the restricted-fed rats and the decreases in plasma ALT activities were in parallel with decreases in food consumption. This is coincident with the phenomenon noted in rats after overnight fasting (Apostolou et al., 1976; Kast and 
Specificity of transaminase activities in drug-induced hepatotoxicity

Nishikawa, 1981; Kale et al., 2009). Starvation induces atrophy of the small intestinal (SI) mucosa with the reduction of brush-border enzymatic activities in animals and humans (Kotler et al., 1982; Chappell et al., 2003; Papavramidis et al., 2009). The decreased ALT activities and tissue weights in the SI mucosa during the early phase of the restricted feeding were considered to be associated with the severely starved condition (Kobayashi et al., 2010). Time course and multiple regression analyses of the alterations in plasma and tissue ALT activity revealed that plasma ALT activities in the restricted-fed rats could be estimated by the ALT activities in the SI mucosa and liver (Fig. 5, Table 3). From these results, the source of transaminase in the blood is not only the liver but also the small intestine under the alteration of nutritional condition.

Elevations of transaminase activities in the blood associated with nutritional or hormonal modifications are slight in magnitude (2- or 3-fold increases compared to baselines) with the change of ALT being more prominent than that of AST, are not exacerbated overtime and are not accompanied by any finding suggestive of tissue damage, including hepatocellular necrosis. The slight increase in transaminase levels in the blood is considered to be due to the release of the enzymes from the organs, where enzyme protein synthesis is accelerated, during circulation from the normal cell turn over. In addition to the gluconeogenesis-related hormones, estrogen is known to increase transaminase levels in the blood without any apparent hepatotoxicity. It is difficult to explain the

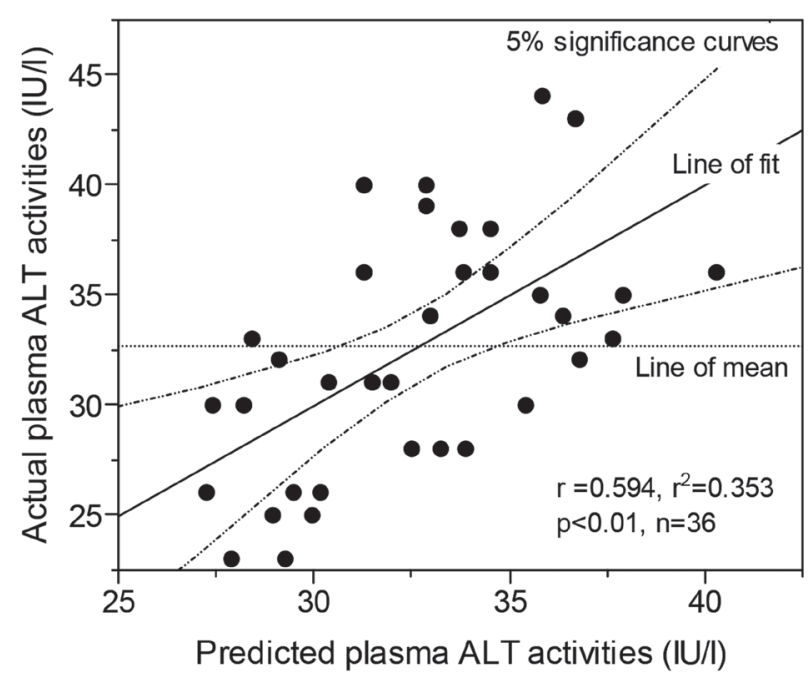

Fig. 5. Multiple regression analysis with the plasma and tissue ALT activities in rats maintained under spaced feeding conditions (Kobayashi et al., 2010). estrogen-related transaminase elevations in the blood by enzyme induction in the liver as discussed for the gluconeogenesis-related hormones. This is because estrogen is known to decelerate gluconeogenesis, inhibit the developmental formation of AST in the fetal liver of rats and prevent the hydrocortisone induction of soluble AST in the liver of adult male rats (Herzfeld and Greengard, 1971). The mechanism of the elevation is considered to be related to non-gluconeogenesis-related enzyme induction in the liver or the release of enzyme proteins from the liver due to alteration of the permeability of plasma membrane (Nagae et al., 1991; Seeman, 1972).

\section{Diseases and other factors}

Mild elevations of transaminases in the blood are noted in patients with several diseases, including diabetes mellitus, glycogenosis (glycogen storage disease) type VI and fatty liver. It has been reported that the serum hepatic function parameters, including AST and ALT, are higher in diabetic patients than in individuals who do not have diabetes (Doi et al., 2007; Dango et al., 2016; Mathur et al., 2016; Kanwar and Saxena, 2018; Roy et al., 2018). The Hisayama study showed that serum GGT and ALT levels are strong predictors of diabetes in the general population, independent of known risk factors (Doi et al., 2007).

Although patients with type 2 diabetes mellitus (T2DM) have concomitant liver disease, including nonalcoholic fatty liver disease (NAFLD) with liver enzyme elevations, the reported prevalence of the liver disease in diabetes differs by clinical study (Tolman et al., 2007) and mild elevations of transaminases cannot be adequately explained by the concomitant liver disease alone. Hepatic gluconeogenesis is accelerated in T2DM patients (Gerich and Nurjhan, 1993) and insulin insufficiency leads to a decrease in rates of glycolysis and increases in gluconeogenesis and glycogenolysis in the liver in diabetic patients (Guo et al., 2012). Insulin resistance is a characteristics feature of both T2DM and obesity, and both obese and lean insulin-resistant individuals manifest multiple disturbances in free fatty acid metabolism (DeFronzo, 2004; Abdul-Ghani et al., 2008). Insulin insufficiency leads to acceleration of catabolism of lipids.

In patients with insulin-dependent diabetes mellitus (type 1), the high transaminase levels may be related to be hormone-related transaminase elevations mentioned above. In patients with T2DM, the high transaminase levels may be related to hepatic insulin resistance, diminished insulin secretion, hyperglucagonemia (excess glucagon secretion), increased hepatic fatty acid oxidation, all of which are potential factors responsible for increased 
A. Kobayashi et al.

Table 3. A linear multiple regression model for estimation of plasma ALT activities from tissue ALT activities in rats maintained under spaced feeding conditions (Kobayashi et al., 2010).

\begin{tabular}{lccc}
\hline Independent variables & Coefficients & $\begin{array}{c}\text { Partial correlations } \\
\text { (vs plasma ALT activities) }\end{array}$ & $\mathrm{p}$ values \\
\hline SI mucosa & 4.194 & 0.461 & 0.0053 \\
Liver & 4.103 & 0.553 & 0.0005 \\
Intercept & 16.85 & - & 0.0001 \\
\hline Multiple correlation coefficient ( $\mathrm{r}$ ) & & 0.594 & 0.0008 \\
r square & & 0.353 & - \\
Number of samples & 36 & - \\
\hline
\end{tabular}

SI mucosa: Small intestinal mucosa. Plasma ALT activities (IU/l) were used as the objective variable. Body weight-adjusted ALT activities per whole tissues (IU/tissue/g BW) in the SI mucosa and liver were selected as the independent variables by the stepwise method.

hepatic gluconeogenesis, or complications, including fatty liver. In glycogenosis type VI and fatty liver, high transaminase levels may be related to fluctuations of glucose or lipid metabolism, however, it is generally accepted that the high transaminase levels are related to release of the enzyme proteins from the hepatocytes to the circulation due to alteration of the permeability of the plasma membrane caused by excessive accumulation of glycogen or lipids in the hepatocytes (Ramaiah, 2007).

In animals, obesity and steatosis have been shown to cause a minor induction of ALT2 in the liver (Jadaho et al., 2004; Aubert et al., 2012). It has been also reported that plasma hepatic function parameters, including ALT and AST, are higher in the Spontaneously Diabetic Torii-Lepr fa (SDT fatty) rats, an animal model for human T2DM, than in healthy rats (Takahashi et al., 2019). The higher levels of hepatic function parameters in SDT fatty rats are not accompanied by any histopathological changes suggestive of hepatotoxicity in the liver. This indicates that the higher levels of hepatic function parameters in the SDT fatty rats are not related to damage to the hepatocytes. In the SDT fatty rats, urinary and plasma glucose levels are higher than in healthy rats. The SDT fatty rats also have higher hepatic Fbp1 mRNA levels (gluconeogenesis-related enzyme), lower Pklr mRNA levels (glycolysis-related enzyme) and lower G6pc mRNA levels (glycolysis-related enzyme) (Takahashi et al., 2019). These indicate that gluconeogenesis is accelerated and glycolysis is decelerated in the SDT fatty rats. The SDT fatty rats also have higher hepatic Cptla mRNA levels (fatty acid $\beta$-oxidation-related enzyme). In the diabetic state, hepatic $\beta$-oxidation is accelerated to synthesize ketone bodies in the liver and ketone bodies are used for ATP production in the peripheral tissues in which utilization of glucose is decreased (Horie et al., 1981; Asayama et al., 1999; Mahendran et al., 2013; Puchalska and Crawford,
2017). Thus, the higher hepatic Cptla mRNA levels in the SDT fatty rats indicates that fatty acid $\beta$-oxidation is also accelerated due to the diabetic state of the animals. From these, the higher ALT and AST levels in the SDT fatty rats are considered to be related to acceleration of hepatic gluconeogenesis (Takahashi et al., 2019).

Based on the results from clinical and non-clinical research in diseases related to impairment of glucose or lipid metabolisms, the higher levels of ALT and AST in the blood are considered to be partially related to enzyme induction in the liver due to the accelerated hepatic gluconeogenesis and multiple disturbances in free fatty acid metabolism.

\section{DRUGS AND TRANSAMINASE ELEVATIONS}

Both in clinical and non-clinical studies, ALT and AST levels in the blood are widely used as sensitive markers of possible tissue damage, particularly liver toxicity (Ramaiah, 2007). In the case of DILI, serum transaminase levels increase up to 100-fold, indicative of marked hepatocyte cell lysis. On the other hand, we sometime encounter mild and transient increases in transaminase levels in the blood without any obvious finding indicative of hepatotoxicity, including alteration of other liver function parameters and degenerative histopathological findings in the liver both in clinical and non-clinical studies for pharmaceuticals. Taking the nutritional and hormonal aspects of the elevation of transaminases into consideration, if a drug affects the amino acid/glucose metabolism pathway by its pharmacological actions, the transaminase activities will be altered in both the tissues and blood. In addition, the transaminase activities may be also altered if the drug affects the lipid metabolism pathway because the lipid metabolism is closely linked to the amino acid/glucose metabolism. Actually, mild and transient elevations of 
Specificity of transaminase activities in drug-induced hepatotoxicity

transaminase are seen especially with drugs which modify lipid and/or glucose metabolism.

Lipid-lowering drugs, such as fibrates and statins (HMG-CoA reductase inhibitors), slightly increase serum transaminase levels (less than three times the upper limit of normal) in humans but there is little evidence that the phenomenon is related to DILI (Tolman, 2000, 2002; Chitturi and George, 2002). Mild and reversible increases in transaminase levels are characteristic of all the lipid-lowering drugs with different pharmacological action, such that the elevation of transaminases is considered to be related to the phenomenon by which lipids are lowered, rather than a direct effect of the drugs (Tolman, 2000).

Treatment with some drugs that modify glucose metabolism as their pharmacological action, such as $\alpha$-glucosidase inhibitors ( $\alpha$-GIs), is sometimes associated with slight and asymptomatic increases in serum transaminase levels in humans (Bomhard, 1996; Gentile et al., 1999). Toxicology studies on lipid-lowering drugs and $\alpha$-GIs have also demonstrated transient increases in transaminase levels in the blood but no histopathological evidence of hepatotoxicity (Tolman, 2000; Bomhard, 1996), although some non-clinical toxicology studies have revealed that very high doses of statins caused hepatocellular necrosis in rabbits (Kornbrust et al., 1989). These clinical and non-clinical findings indicate that mild, reversible and asymptomatic transaminase elevations do not necessarily reflect hepatotoxicity.

\section{Fibrates}

Fibrates, PPAR $\alpha$ activators, are widely used as one of lipid-lowering drugs. Fibrates have been shown to modify a variety of aspects of lipid metabolism, leading to reductions in blood lipid levels (Balfour et al., 1990, Blane, 1987). Possible mechanisms of the lipid-lowering action of fenofibrate include an increase in lipoprotein-lipase synthesis, activation of $\beta$-oxidation of free fatty acids and repression of the Apo C-III gene, through PPAR $\alpha$ activation, which lead to acceleration of triglyceride catabolism and repression of triglyceride synthesis.

It has been reported that serum ALT and AST levels are increased in some patients who received fibrates (Balfour et al., 1990; Blane, 1987). In general, the increase is mild (less than three times the upper limit of normal), sometimes transient and is not accompanied by any finding suggestive of hepatotoxicity. The results of biopsy of the liver from patients who received fenofibrate over a long time have revealed that there were no histopathological findings suggestive of DILI although transaminase levels in the blood had been increased before biop- sy (Blane, 1987). The increase in serum transaminases seen in patients treated with fibrates is commonly a transient phenomenon roughly following reciprocal changes in serum triglyceride levels (Edgar et al., 1998).

From the results of in vitro studies, fenofibrate has been also shown to modify the expression of the ALT and AST genes in animal and human hepatocytes and to increase the activities of these enzymes in a PPAR $\alpha$-dependent manner in human hepatocytes (Edgar et al., 1998; Tomkiewicz et al., 2004; Thulin et al., 2008). The gene modification and elevations of the enzyme activities of ALT and AST in the hepatocytes are considered to be related to the pharmacological action of fenofibrate, independently of any toxic phenomenon (Edgar et al., 1998; Tomkiewicz et al., 2004). PPAR $\alpha$ specifically controls expression of the GPT1 gene. Fenofibrate induced expression of ALT and increased binding of PPAR $\alpha$ to the GPT1 promotor in cultured human hepatocytes (Thulin et al., 2008). From these findings, PPAR $\alpha$ plays a role in regulation of transaminase levels, particularly ALT1. Elevations of ALT levels in the blood have been also reported in fenofibrate-treated rats and dogs and bezafibrate-treated monkeys in nonclinical toxicology studies (Sameshima et al., 1995a, 1995b; Chesterman et al., 1988). These changes were mild, transient and not dosedependent and were not accompanied by histopathological findings in the liver suggestive of hepatotoxicity.

An in vivo study has also strongly indicated that the elevation of plasma transaminases after treatment with fenofibrate is related to its pharmacology but not to hepatotoxicity (Kobayashi et al., 2009). In this study, male F344/DuCrlCrlj (Fischer) rats were treated once with fenofibrate and the relationships between the pharmacological effects, plasma and hepatic transaminase activities and the gene expression of the transaminases in the liver were investigated. Fenofibrate treatment slightly increased plasma transaminase activities, including mitochondriatype AST, in rats with the findings directly related to the pharmacological action of the drug. The increases were in parallel with increases in hepatic transaminase activities, including mitochondrial ALT and AST, associated with increases in the transaminase genes (mitochondrial AST) in the liver and were not considered to be a consequence of hepatotoxicity from the drug because of the absence of alterations of other liver function tests and of histopathological findings suggestive of hepatotoxicity. Blood and hepatic AST activities are known to be less sensitive than ALT activities in humans and rats treated with PPAR $\alpha$ agonists (Balfour et al., 1990; Blane, 1987; Kobayashi et al., 2009). The modification in hepatic transaminase gene expression is likely to be secondary to the pharmacologi- 
cal action of fenofibrate. This discussion was based on the good negative correlation between the plasma triglyceride levels, as an indicator of the pharmacological action, and plasma transaminase levels in fenofibrate-treated animals (Kobayashi et al., 2009) (Fig. 6).

The evidence obtained in these in vitro and in vivo studies underlines the importance of gene regulation as a possible alternative mechanism for increased transaminase activities in the blood.

\section{Statins}

Statins lower plasma cholesterol via inhibiting 3-hydroxy-3-methylglutaryl-CoA (HMG-CoA) reductase in the liver in humans (Singer et al., 1984, 1988). Statins also increase mitochondrial and peroxisomal fatty acid oxidation ( $\beta$-oxidation) in the liver in mice and this phenomenon is independent of their effect of decreasing cholesterol levels; the phenomenon can be extended to humans (Park et al., 2016). Although there are clearly documented reports of hepatotoxicity with statins in humans, including acute liver failure, the overall frequency of serious liver injury ( 0.2 per 100,000 persons exposed) is lower than that of the background population and considerably less than that associated with drugs such as the NSAIDs (Chitturi and George, 2002). The transaminase elevations (primarily serum ALT) are seen in a small percentage of patients receiving simvastatin and lovastatin in clinical trials (Walker, 1989; Tolman, 2002). Patients experiencing these elevations are completely asymptomatic, and preliminary evidence suggests that these elevations resolve spontaneously, despite continued dosing with the drug. Therefore, monitoring hepatotoxicity has not been effective in preventing seri- ous liver disease, largely because of its rarity and the poor predictive value of monitor ALT elevations (Tolman, 2002).

In nonclinical toxicology studies, transient increases in serum transaminase activities (primarily serum ALT) are also observed in a small percentage of dogs receiving simvastatin (Gerson et al., 1989). However, no evidence of any hepatic damage has been observed after the administration of high dosages of simvastatin to dogs. The elevations can be anywhere from slightly above baseline to levels approximately 10 times the normal baseline level. Although the duration of increased serum transaminase activity varies, all the elevations have been transient, resolving spontaneously to baseline levels despite continued administration of simvastatin. None has progressed to levels indicative of frank hepatotoxicity, and not all dogs have experienced these elevations. Furthermore, affected dogs were otherwise asymptomatic; there are no corroborating physical signs, or a decrease in body weight gain or food consumption. In addition, no other extrahepatic source of serum ALT activity (i.e., cardiac or skeletal muscle) has been identified as a potential source of these elevations. Lovastatin also caused slight elevations of serum ALT in chronic toxicology studies in dogs but no histologic liver damage (MacDonald et al., 1988). In pravastatin, serum ALT and AST levels increased in monkeys and dogs but not in rats (Manabe et al., 1989a; Tarumi et al., 1989; Kimura et al., 1987). The elevations were not accompanied by liver injury although elevations at high dose levels were accompanied by liver injury which was considered to be related to the pharmacological action of pravastatin (Manabe et al., 1989b). From these observations, there appear to be some similarities
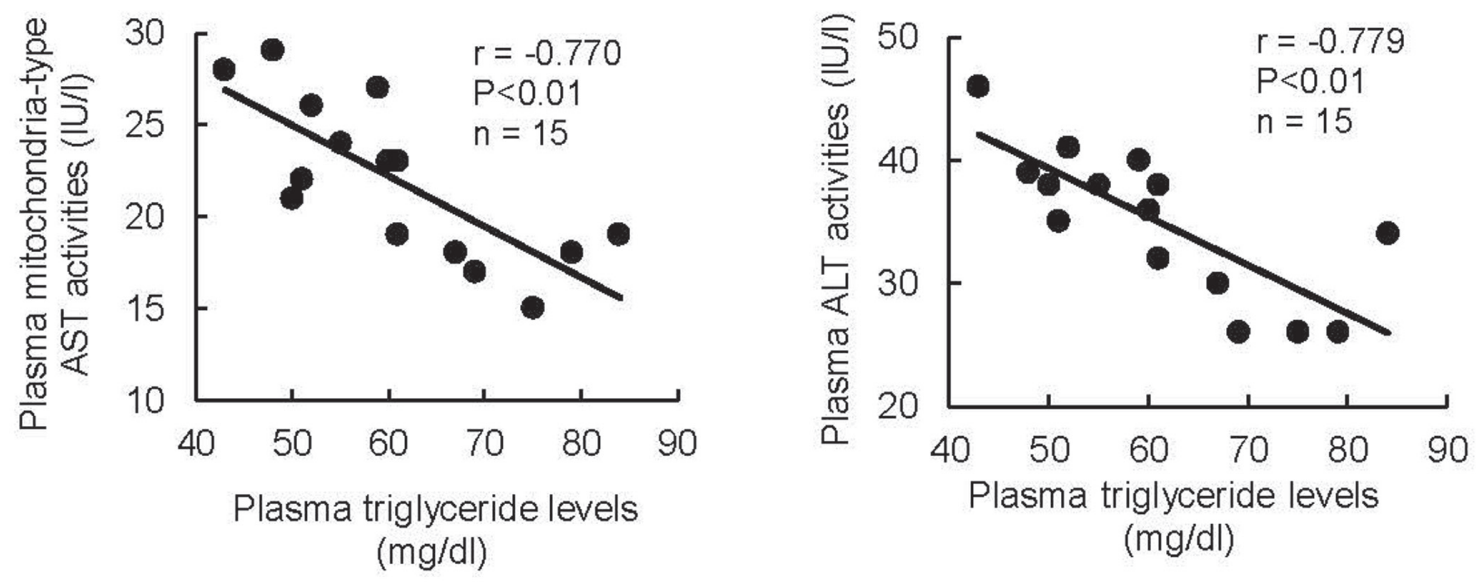

Fig. 6. The correlation between pharmacological action and plasma transaminase levels in the fenofibrate-treated animals (Kobayashi et al., 2009). 
Specificity of transaminase activities in drug-induced hepatotoxicity

between the transient transaminase elevations seen in dogs receiving statins in nonclinical toxicology studies and the transaminase elevations seen in patients receiving statins (MacDonald et al., 1988; Walker, 1989). In preliminary experiments conducted with lovastatin, mevalonic acid supplementation appeared to protect against the development of transaminase elevations in dogs (MacDonald et al., 1988), thereby suggesting that interference with mevalonate synthesis might be responsible for these elevations.

\section{a-Glucosidase inhibitors ( $\alpha$-GIs)}

The $\alpha$-GIs are used as adjuvant therapy in type 2 diabetes. They ameliorate postprandial glycemia by interfering with digestion of dietary polysaccharides. Acarbose has been incriminated in several reports of dose-related hepatotoxicity, usually at doses in excess of $100 \mathrm{mg} /$ day, and complete recovery follows drug withdrawal (Chitturi and George, 2002). Other glucosidase inhibitors include voglibose, which has been associated with intrahepatic cholestasis, and miglitol and the latter has not been associated with hepatotoxicity (Chitturi and George, 2002). Although $\alpha$-GIs have been reported to be associated with several rare adverse hepatic events (Andrade et al., 1996; Carrascosa et al., 1997; Gentile et al., 1999) and an increase in transaminase levels (Hollander, 1992; Coniff, et al., 1994, 1995a, 1995b, 1995c; Lam et al., 1998; Iwamoto et al., 2010), a causal relationship has not been established (Zhang et al., 2016).

In non-clinical toxicology studies, increased transaminase activity in the blood is also noted in animals (rats and dogs) (Bomhard, 1996). The elevations are generally slight and are not accompanied by any findings suggestive of hepatotoxicity, although slight single cell necrosis of the hepatocytes was observed in a small percentage of rats receiving high doses of voglibose for 5 weeks. Interestingly, in dogs, only moderately increased AST activities occurred after treatment with emiglitate and miglitol (Bomhard, 1996). In the dog, as a carnivorous species, gluconeogenesis from amino acids is normally much higher than in the rat, which would explain why the dog was less responsive with regard to the induction of these enzymes. The lack of a consistent effect on these enzymes even after subacute high-dose parenteral treatment with acarbose, emiglitate and miglitol in rats and dogs argues against a compound-related hepatotoxic potential (Bomhard, 1996). When administered shortly before or simultaneously with feed, the $\alpha$-GIs by their intrinsic properties reduce glucose utilization to an extent where the isocaloric state can be lost. Severe body weight retardation is one of the consequences seen in animals after receiving $\alpha$-GIs. On the organ level (liver and kidney), signs of increased gluconeogenesis from glucogenic amino acids occurred (Bomhard, 1996). In the liver, this results in an induction of enzymes involved in the amino acid/glucose metabolism such as ALT and AST. This discussion is supported by the finding that feeding high glucose levels $(66.1 \%)$ to voglibose-treated Wistar rats completely prevented the rise in plasma ALT and AST activity and that the activities of hepatic ALT and AST were markedly increased in voglibose-treated rats fed a low-protein diet but not on the low-protein glucose or the commercial diet (Suzuki et al., 1991). Thus, the elevation of transaminases in the voglibose-treated rats is considered to have been caused by excessive manifestation of the pharmacological activity of voglibose.

Increased activities of both enzymes in the blood can best be explained in this way, which have been observed at high oral doses of acarbose, emiglitate and voglibose in the rat (Bomhard, 1996).

\section{Acyl CoA: diacylglycerol acyltransferase 1 (DGAT1) inhibitor}

The glycerol phosphate and the monoacylglycerol pathway are two major pathways for triglyceride (TG) biosynthesis (Kennedy, 1957; Bell and Coleman, 1980; Lehner and Kuksis, 1996; Coleman and Lee, 2004). In the final reaction for both pathways, a fatty acyl-CoA and diacylglycerol molecule are covalently joined to form TG. This reaction is catalyzed by DGAT enzymes. The genes encoding two DGAT enzymes, DGAT1 and DGAT2, have been identified (Oelkers et al., 1998; Lardizabal et al., 2001). DGAT enzymes are expressed in numerous organs. Particularly, DGAT1 is highly expressed in the small intestine and fat tissues while DGAT2 is highly expressed in the liver and fat tissues (Unger, 2002; Cases et al., 2001).

In DGAT1-transgenic mice that highly express DGAT1 specifically in fat tissues, accumulation of TG in fatty tissues accompanied by marked increases in body weight is observed when the animals are fed a high-fat diet (Chen et al., 2002). Conversely, DGAT1 knockout mice show resistance to the obesogenic effects of a highfat diet (Smith et al., 2000). DGAT1 knockout mice fed a high-fat diet maintain body weights comparable to mice fed a regular diet. TG levels in the liver and skeletal muscles are lower and increased energy expenditure is observed in DGAT1 knockout mice when compared with wild type mice. DGAT1 knockout mice have increased insulin and leptin sensitivity when compared with wildtype littermates. Therefore, the phenotypes for DGAT1 gene polymorphisms in humans and DGAT1 deficiencies 
A. Kobayashi et al.

in mice have generated considerable interest for DGAT1 inhibitors as a potential therapy for obesity.

After repeated oral dosing of a DGAT1 inhibitor in rats and monkeys, plasma transaminase levels were increased but there were neither changes in other hepatic function parameters nor histopathological findings suggestive of hepatotoxicity (Yokoyama et al., 2018). The increase in plasma transaminase levels was noted in monkeys at lower dose levels with lower systemic exposure than in rats (AUC: 9 to $33 \mu \mathrm{g} \cdot \mathrm{hr} / \mathrm{mL}$ at $1 \mathrm{mg} / \mathrm{kg}$ and AUC: 221 to $395 \mu \mathrm{g} \cdot \mathrm{hr} / \mathrm{mL}$ at $100 \mathrm{mg} / \mathrm{kg}$ in monkeys and rats, respectively) and monkeys were more sensitive than rats for the elevation of transaminases. The findings related to the pharmacological action of the DGAT1 inhibitor, including decreased plasma triglyceride levels and accumulation of fatty acids in the epithelial cells in the small intestine, were noted in monkeys at lower dose levels than in rats. Based on the results of exploratory studies for investigation of the mechanism of the increase in transaminase levels, plasma transaminase levels were increased even after single oral dosing the DGAT1 inhibitor only when animals were fed after dosing and a main factor in the diet contributing to the increase in plasma transaminase levels was lipids (Yokoyama et al., 2018). After dosing the DGAT1 inhibitor, transaminase activities were increased in the small intestine but not in the liver, indicating that the origin of transaminase increased in the plasma was not the liver but the small intestine, where the DGAT1 inhibitor exhibits its pharmacological action. The increase in small intestinal transaminase levels was due to increased enzyme protein synthesis and was suppressed by co-administration of orlistat (a lipase inhibitor), which inhibits fatty acid-transport to the enterocytes (Yokoyama et al., 2018). Interestingly, the plasma transaminase that was increased after dosing the DGAT1 inhibitor in dogs, in which AST activity is much higher than ALT activity in the small intestine, was AST, not ALT, and the response to the DGAT1 inhibitor in dogs was different from that in rats and monkeys, in both of which ALT activity is equal to or higher than AST activity in the small intestine. The increase in transaminase levels in the small intestine after dosing the DGAT1 inhibitor was considered to be related to acceleration of beta-oxidation for degradation of the fatty acids accumulated in the small intestine as the result of the pharmacological action of the DGAT1 inhibitor (inhibition of the re-synthesis of triglycerides from free fatty acids and diacylglycerol). In other words, the DGAT1 inhibitor-related increase in plasma transaminase levels is considered not to be due to release of the enzymes from injured cells into the circulation but to be phenomena resulting from enhancement of enzyme pro- tein synthesis in the small intestine due to the pharmacological action of the DGAT1 inhibitor in this organ.

\section{Microsomal triglyceride transfer protein (MTP) inhibitor}

It has been reported that treatment with an inhibitor of the MTP increased levels of ALT1 and AST1 in both lysates and medium from Huf-7 cells. It has been reported that IRE1 $\alpha / \mathrm{c}$-Jun signaling control expression of ALT and AST and knockdown of either IRE1 $\alpha$ or c-Jun prevented the MTP inhibitor-induced increases in ALT1 and AST1 in Huf-7 cells (Josekutty et al., 2013).

In summary, drugs modifying amino acid/glucose/lipid metabolism are associated with mild elevations of transaminase in the blood. The common profile of the elevations of transaminases in these drugs is as follows:

1) The elevations are asymptomatic and are not enhanced along with prolongation of the dosing period or rather are reversible despite continuation of dosing.

2) Absence of alterations of other liver function tests, including LDH, ALP and BIL

3) As well as transaminase elevations in alteration of nutritional or hormonal conditions, ALT is more sensitive than AST in most cases, except for dogs after dosing $\alpha$-GIs and DGAT1 inhibitor.

4) The elevation can be seen at the pharmacological dose or at dose levels close to the pharmacological dose.

5) The elevation is correlated with the pharmacological action.

These profiles noted in drugs modifying glucose/lipid metabolism are similar to those noted in the nutritional or hormonal fluctuations mentioned above. The transaminase elevations with these profiles can be called "pharmacology-related transaminase elevations". This definition is supported by evidence that the transaminase elevations in drugs modifying glucose/lipid metabolism can be cancelled by inhibition of the pharmacological actions of these drugs, as shown in statins by supplementation with mevalonic acid, $\alpha$-GIs with feeding of high glucose levels and DGAT1 inhibitor with a lipase inhibitor or by knockdown of either IRE1 $\alpha$ or c-Jun in the MTP inhibitor (Gerson et al., 1989; Bomhard et al., 1996; Bomhard, 1996; Yokoyama et al., 2018; Josekutty et al., 2013). 
Specificity of transaminase activities in drug-induced hepatotoxicity

\section{DIFFERENCES IN PROFILE OF TRANSAMINASE ELEVATIONS BETWEEN THE PHARMACOLOGY-RELATED AND HEPATOTOXICITY-RELATED ELEVATIONS}

Although the leakage of hepatocellular enzymes into the circulation is usually considered evidence of hepatotoxicity, the spontaneous resolution of these transaminase elevations is not characteristic of continued dosing with a classic hepatotoxicant. Some of the important differences in the profiles between the nutrition-related or pharmacology-related and hepatotoxicity-related transaminase elevations are those in the magnitude of the elevations and the predominance of the increase in AST or ALT.

In the case of hepatotoxicity, transaminase activities in the blood increase markedly in a dose-dependent manner and AST/ALT activity ratio increases along with progression of the hepatic damage. On the other hand, in most cases of the pharmacology-related elevations, the transaminase elevations are mild (up to 10-fold) with plateau of the elevations and the elevation of ALT activity is more prominent than that of AST activity.

The mechanisms of transaminase elevations in the blood may differ between the pharmacology-related elevations and hepatotoxicity-related elevations. McGill (2016) discussed in his review that although plasma membrane damage and protein leakage is probably the most common reason for elevated serum ALT, there is evidence that other mechanisms can be involved. The mechanisms include oncotic necrosis, membrane blebbing, increased expression and macroenzymes. Additional possible mechanisms for the transaminase elevation may include decreased transaminase clearance and transaminase leakage from cells whose membranes may have been altered by changes in their lipid content. The pharmacology-related transaminase elevations are considered not to be related to oncotic necrosis but to be related to other mechanisms, mainly increased expression of the enzyme. Several mechanisms have been proposed for regulation of transaminase expression, including PPAR $\alpha$ (Edgar et al., 1998), PI3K-ATF4 axis (Hao et al., 2016) and IRE1 $\alpha / \mathrm{c}-J u n$ signaling (Josekutty et al., 2013). Based on these findings, the mild increase in transaminase activities in the blood reported in drugs modifying lipid/glucose metabolism can be explained by the release of transaminase enzyme proteins, which are increased in the cell through increased gene expression, into the circulation through mechanisms different from plasma or mitochondrial membrane destruction. The difference in predominance of the change in ALT or AST is considered to be related to the difference in total quantity of enzymes in the liver and in the subcellular distribution of enzymes between ALT and AST. The total quantity of AST in the liver is larger than that of ALT and ALT activity is higher in the cytosol while the most AST exists in the mitochondria (DeRosa and Swick, 1975; Gubern et al., 1990; Baumber and Doonan, 1976; Rej, 1978).

In the case of serious hepatotoxicity, the AST/ALT ratio in the blood increases possibly due to the release of AST derived from mitochondria into the circulation as the consequence of destruction of the mitochondrial membrane (Ramaiah, 2007).

In the case of enzyme induction due to acceleration of hepatic gluconeogenesis, although there are no significant changes in transaminase activities in the mitochondria, transaminase activities are increased in the cytosol (Katsunuma et al., 1966). ALT1 (cytosolic ALT) is known to be the dominant form of ALT in the liver (Lindblom et al., 2007). On the other hand, it has also been suggested that the mitochondrial isoform of ALT is particularly important in gluconeogenesis in some cases (McCommis et al., 2015). ALT is easily solubilized from mitochondria, but AST is not (Katsunuma et al., 1966).

The difference in the half-life between ALT and AST in the circulation may partly explains the predominance of the pharmacology-related elevation of ALT. The halflife of AST (0.7-4.7 hr) in the circulation is much shorter than that of ALT (72-84 hr) in rats (Kamimoto et al., 1985; Kim, 1969). This discussion can be also applied to the predominance of the elevation of ALT activity in the blood associated with nutritional or hormonal modifications, because gene expression and enzyme protein synthesis are accelerated for both ALT and AST in the organs in some cases.

\section{SPECIES DIFFERNECES IN PHARMACOLOGY- RELATED ELEVATION OF TRANSAMINASE ACTIVITIES}

The pharmacology-related elevations of transaminases in the blood after receiving fibrates, statins and $\alpha$-GIs have been reported not only in humans but also in animals, as mentioned above. There are, however, animal species differences in the response of transaminases to these drugs despite similar systemic exposure to drugs between species without any significant differences in metabolite profiles.

Non-rodents, including dogs and monkeys, are considered to be more sensitive than rodents in terms of the pharmacology-related elevations of transaminases after receiving statins, fibrates and DGAT1 inhibitors (Gerson et al., 1989; MacDonald et al., 1988; Chesterman et al., 
1988; Sameshima et al., 1995a; Yokoyama et al., 2018) and the profile of transaminase elevations of these non-rodent animals species is similar to that in humans. The difference may be related to difference in energy consumption and glucose/lipid metabolism between rodents and non-rodents and there seems to be mainly two reasons for the similarity of the pharmacology-related transaminase elevations between non-rodents and humans. The first reason is a difference in feeding status in nonclinical toxicology studies between rodents and non-rodents. In rats and mice, basal diet is given ad libitum (free access to diets $24 \mathrm{hr}$ a day) to animals and they eat the diet mainly at night. In dogs and monkeys, on the other hand, the basal diet, the amount of which is the minimum required to maintain animals' health, is given once or twice daily at a specified time. Therefore, the degree of hunger is considered to be greater in non-rodents than in rodents in nonclinical toxicology studies. Actually, this discussion could be validated by studies on rodents receiving drugs with feeding routine similar to that employed for non-rodents in toxicology studies. In the case of the DGAT1 inhibitor, plasma ALT levels were increased markedly in rats to the same extent as in monkeys when rats received the inhibitor with feeding routine similar to that employed in the toxicology study in monkeys (Yokoyama et al., 2018).

The second reason is the species differences in glucose and lipid metabolism. Especially, the mechanism for maintenance of blood glucose levels in dogs is different from that in rodents in a fasting state. In dogs, blood glucagon levels are not influenced by long-term fasting (de Bruijne et al., 1981) and the rate of hepatic glycogenolysis is lower than in rats during starvation (de Bruijne and de Koster, 1983; Remesar and Alemany, 1980; Shikama et al., 1980). Dogs do not develop significant hypoglycemia during 1 week of total starvation (Altszuler et al., 1974; de Bruijne et al., 1981), despite their lower rate of glycogenolysis. The mechanism for the maintenance of blood glucose levels in dogs in a fasted state can be explained by acceleration of gluconeogenesis using the gluconeogenic precursors, alanine and lactate, (Remesar and Alemany, 1980; Shikama et al., 1980; Soling and Kleineke, 1976; Belo et al., 1977; Freminet and Leclerc, 1980) and the contribution of hepatic gluconeogenesis to the maintenance of blood glucose in a fasted state is considered to be greater in dogs than in rats.

Considering these two reasons, non-rodents are put in the situation where hepatic gluconeogenesis is easily accelerated when compared with rodents in nonclinical toxicology studies. The more prominent transaminase elevations in the blood in non-rodents are considered to be due to a phenomenon resulting from enhancement of enzyme protein synthesis in the gluconeogenic organs following gluconeogenesis accelerated by the pharmacological actions of lipid- or glucose-lowering drugs, in combination with physiological responses to starvation when these drugs are dosed to animals in a fasted condition. This discussion is supported by evidence that the pharmacological changes, including decreased blood lipid levels, as well as transaminase elevations are observed more prominently in non-rodents than in rodents after receiving lipid-lowering drugs such as pravastatin (Kimura et al., 1987; Manabe et al., 1989a, 1989b; Tarumi et al., 1989), fenofibrate (Sameshima et al., 1995a, 1995b) and DGAT1 inhibitor (Yokoyama et al., 2018).

The opposite direction of the changes in activity or gene expression of cytosolic AST in the liver after treatment with fenofibrate between wild and gene deficient animals and between animals and humans has been reported by several researchers (Edgar et al., 1998; Tomkiewicz et al., 2004; Kobayashi et al., 2009). Although the etiology of the opposite direction of the changes in cytosolic AST activities and mRNA levels in human and rat cells is not well known, differences in the regulation of the cytosolic AST genes by PPAR $\alpha$ activation between rodents and human have been proposed.

The species difference in the predominance of ALT or AST in the pharmacology-related elevations of transaminases in the blood may give useful information on the source of the increased transaminases in the blood. In the case of the DGAT1 inhibitor, the transaminase increased in the plasma was AST in dogs, while elevation of ALT was more prominent than that of AST in rats and monkeys (Yokoyama et al., 2018). The source of the increased transaminase in the plasma was identified to be the small intestine in animals receiving the DGAT1 inhibitor (Yokoyama et al., 2018). As well as the DGAT1 inhibitor, the transaminase increased in the serum was AST in dogs receiving $\alpha$-GIs (Bomhard, 1996). The primary pharmacological target organ is the small intestine for both DGAT1 inhibitor and $\alpha$-GI. Although the source of transaminase has not been identified in animals receiving $\alpha$-GIs, the small intestine should be taken into account as the source of transaminase increased in the serum from the pharmacological aspect of $\alpha$-GIs and from the evidence that there are species differences in the predominance of the transaminase increased in the serum or plasma.

\section{TRANSAMINASES AND ESTIMATION OF RISK OF DILI}

First, the profiling of elevation of transaminases in the blood is necessary when slight and isolated elevation of 
Specificity of transaminase activities in drug-induced hepatotoxicity

transaminases is noted in nonclinical toxicology studies (Table 4). Taking into account the specific activity of transaminases in the liver tissue and the relatively large size of the liver, if hepatocytes were to be damaged by drugs, the blood enzyme levels should be increased markedly. On the other hand, in the case of the pharmacologyrelated elevations of transaminases due to enhancement of enzyme protein synthesis in the tissues/organs, the increase is slight and is not exaggerated, along with the prolongation of the dosing period or is ameliorated even though continuation of dosing with a drug. Therefore, the magnitude of the elevation will be one of the indicators to predict the potential risk of DILI both in nonclinical and clinical studies. Dose-response relationship analyses are also sometimes useful because in the case of DILI clear dose-responses can be seen in the elevation of blood transaminase levels while the pharmacology-related elevation of transaminases may reach a plateau after saturation of the pharmacological action of a drug. To examine whether the increase in transaminase is accompanied by increases in other parameters-related to hepatotoxicity, including ALP, LDH and total BIL levels, would help the differentiation of the pharmacology-related transaminase elevation from transaminase elevation from DILI. In nonclinical toxicology studies, histopathological findings in the liver and other organs, including the skeletal muscles and intestine, and measurements of transaminase activity of the organs/tissues which are considered to be the target of pharmacology or toxicity may also help the differentiation.

In the case of isolated elevations of transaminases in the blood, comparisons of the magnitude of the elevation of the transaminase or alterations of blood glucose and lipid parameters, if any, between animal species are sometimes useful to determine whether the transaminase elevation is pharmacology-related or not. If there is a species difference in the transaminase elevation and it is difficult to explain the difference from pharmacokinetic point of view, such as systemic exposure to the parent drug or its metabolite, their protein binding ratio and tissue distribution, there is a possibility that the elevation of transaminase is not related to hepatotoxicity. In such a case, it is necessary to carefully examine animals' physical condition, clinical chemistry parameters which are related to glucose or lipid metabolism and to investigate whether there are species differences in the alterations of these parameters, if any, as well as the elevation of transaminase. Correlation analyses using individual data of transaminase activity and those of glucose or lipid metabolism-related parameters are sometimes useful.

Even in clinical trials, when isolated elevations of serum transaminases are observed, not only careful monitoring of other liver function tests but also profiling of transaminase elevations, including analyses of the magnitude of elevations, AST/ALT ratio and dose- and timedependency, are necessary. Especially in phase I clinical trials, any nutritional or environmental factors leading to alteration of glucose/lipid metabolism, including alteration of calorie intake from the meals, sudden alteration of body weights, and any stressful conditions such as fasting or vigorous exercise, should be investigated. These investigations are important to estimate the mechanism of transaminase elevations and the risk of DILI and to make decisions in the escalation of dose level and continuation of dosing for investigational drugs. In phase II and phase III trials, especially for investigational drugs modifying glucose/lipid metabolism as their pharmacological actions, it is necessary to investigate relationships between alterations of primary or secondary pharmacological endpoints (glucose and lipid levels), characteristics of the patients and complications (BMI and fatty liver etc.) and lifestyle (alcohol and calorie intake) and the transaminase elevations in addition to the items mentioned above. Unlike the nonclinical toxicology studies, it is difficult to differentiate the pharmacology-related elevation of transaminase from transaminase elevation related to DILI when only serum transaminase levels are slightly increased in the clinical trials because it is difficult to conduct liver biopsy or measurement of enzyme activity in tissues/organs in humans. Therefore, communication between toxicologists and clinicians is also necessary to discuss the etiology of transaminase elevations in clinical trials.

The pharmacology-related elevation of transaminase, as detected in lipid-lowering drugs, is considered to occur at dose levels which are close to the pharmacological effective dose or therapeutic dose levels of drugs. On the hand, slight elevations of transaminases are also the early sign of idiosyncratic DILI which also occurs at the therapeutic dose levels. If a slight elevation of transaminase is related to the pharmacology of a drug, however, regarded as the early signs of DILI by clinicians or toxicologists, this would lead to overestimation of the risk of DILI. On the other hand, if the slight elevation is related to early sign of DILI, however, regarded as pharmacology-related, this would lead to underestimation of the risk of DILI. Therefore, careful data analyses and additional investigations are necessary in non-clinical and clinical studies in order to avoid the overestimation and underestimation when slight elevation of transaminase was noted in clinical studies.

In order to avoid overestimation of the risk of DILI, 
A. Kobayashi et al.

Table 4. Items to be investigated when plasma or serum transaminase elevations are noted in nonclinical toxicology studies and in clinical trials of drug candidates.

\begin{tabular}{|c|c|}
\hline Items & Investigation \\
\hline $\begin{array}{l}\text { Profile of changes in serum or } \\
\text { plasma transaminase activities }\end{array}$ & $\begin{array}{l}\text { The magnitude of the increase in transaminase activities when compared with the control or pre- } \\
\text { dosing levels } \\
\text { Dose-response relationship in the transaminase elevations with or without plateau of the } \\
\text { elevations } \\
\text { - AST/ALT ratio } \\
\text { Time sequence analysis of the elevations to investigate whether the elevations enhance with } \\
\text { prolongation of the dosing period } \\
\text { - Reversibility of the elevations or disappearance of the elevations despite continued dosing }\end{array}$ \\
\hline $\begin{array}{l}\text { Relationships between the } \\
\text { transaminase elevations and organ } \\
\text { toxicity }\end{array}$ & $\begin{array}{l}\text { - Any alteration of other liver function tests } \\
\text { - Mitochondria type AST elevation } \\
\text { - Histopathological findings suggestive of organ toxicity (hepatotoxicity, myotoxicity, myocardial } \\
\text { toxicity) related to the transaminase elevations }\end{array}$ \\
\hline $\begin{array}{l}\text { Relationships between the } \\
\text { transaminase elevations and } \\
\text { pharmacology of the drug } \\
\text { candidates }\end{array}$ & $\begin{array}{l}\text { Drug candidate can modify glucose or lipid metabolism } \\
\text { Relationships between the transaminase levels and changes in blood levels of glucose or lipid } \\
\text { parameters } \\
\text { - Relationships between the transaminase levels and other pharmacology-related parameters }\end{array}$ \\
\hline $\begin{array}{l}\text { Relationships between the } \\
\text { transaminase elevations and } \\
\text { modification of nutritional states }\end{array}$ & $\begin{array}{l}\text { Relationships between the transaminase elevations and alterations of food consumption, food } \\
\text { efficiency, body weights and blood levels of glucose and lipids } \\
\text { - Feeding condition: restricted feeding, supplementation of glucose } \\
\text { - Motor activity of animals } \\
\text { - Endogenous metabolite levels related to gluconeogenesis }\end{array}$ \\
\hline $\begin{array}{l}\text { Relationships between the } \\
\text { transaminase elevations and } \\
\text { modification of hormonal states }\end{array}$ & $\begin{array}{l}\text { - Alteration of hormone levels related to glucose/lipid metabolism: insulin, glucagon, corticoid } \\
\text { levels }\end{array}$ \\
\hline $\begin{array}{l}\text { Species differences in the } \\
\text { transaminase elevations }\end{array}$ & $\begin{array}{l}\text { Species difference in the response to the pharmacological action of a drug candidate which } \\
\text { modify glucose/lipid metabolite } \\
\text { Species difference in the magnitude of the serum or plasma transaminase activity: non-rodents } \\
\text { versus rodents }\end{array}$ \\
\hline $\begin{array}{l}\text { The origin of transaminases } \\
\text { elevated in the plasma or serum }\end{array}$ & - Activities of transaminases in organs/tissues: liver, small intestine, kidney, muscle and heart \\
\hline
\end{tabular}

mechanistic studies, including inhibition of the pharmacology of a compound as conducted with statins, and DGAT1 and MTP inhibitors, are considered to be useful. Measurements of mRNA or activities of glucose/lipid metabolism-related enzymes including PC, PEPCK and CPT1, in the liver are also useful to clarify the elevations of transaminases are related to alterations of glucose or lipid metabolism. If species differences are noted and non-rodents are more sensitive in elevations of transaminases to an investigational drug, employment of spaced feeding or modification of the diet for rodents may be useful.

In order to avoid underestimation of the risk of DILI, one of the classic approaches is estimation of DILI based on the Hy's law, taking into alteration of parameters related to liver function, such as serum total bilirubin levels (Zimmerman, 1999; Temple, 2001; Reuben, 2004). This approach, however, can hardly be applied to clinical tri- als conducted in development stage of new investigational drugs because of the small number of subjects enrolled in the clinical trials.

In these circumstances, new biomarkers more specific to DILI are needed. The new biomarkers of DILI include biomarkers for mitochondrial damage, cell death, DNA damage and inflammation and nucleic acid biomarkers and have been reviewed in detail elsewhere (McGill, 2016). As one of these biomarkers, GLDH level in the blood is considered to be a more specific biomarker of DILI than transaminases and it has been reported that, in APAP-induced hepatotoxicity in rats, plasma GLDH level is more sensitive than plasma ALT level (O'Brien et al., 2000; Kondo et al., 2012). This is considered to be related to the difference of localization in the liver between GLDH and ALT (Schmidt and Schmidt, 1988; Hildebrand, 1983). Additional nonclinical and clinical studies and translational research are needed to inves- 
Specificity of transaminase activities in drug-induced hepatotoxicity

tigate the useful ness of these new biomarkers for the assessment of risk of DILI.

\section{CONCLUSION}

Although transaminase activities in the blood are useful markers for DILI, careful consideration should be applied when transaminase activities are slightly increased in nonclinical toxicology studies of drug candidates and in clinical trials of investigational drugs. This is because transaminases are sometimes increased directly or secondarily related to the pharmacology of drugs. In order to differentiate the pharmacology-related transaminase elevations from DILI-related transaminase elevations, profiling of the elevations and mechanistic studies should be conducted in nonclinical studies and careful monitoring should be conducted in clinical trials. Slight and asymptomatic elevations of transaminases sometimes lead to overestimation or underestimation of the risk of DILI, and then more specific biomarkers are necessary to appropriately estimate the risk of DILI.

\section{ACKNOWLEDGMENTS}

The author would like to thank the invaluable contributions of the staff at the Toxicology Research Lab., Central Pharmaceutical Research Institute, JAPAN TOBACCO INC. We would like to also acknowledge Dr. Kazuhiko Matsumoto, Nagoya City University Graduate School of Medical Sciences, for his interest and support during this study.

Conflict of interest---- The authors declare that there is no conflict of interest.

\section{REFERENCES}

Abdul-Ghani, M.A., Muller, F.L., Liu, Y., Chavez, A.O., Balas, B., Zuo, P., Chang, Z., Tripathy, D., Jani, R., Molina-Carrion, M., Monroy, A., Folli, F., Van Remmen, H. and DeFronzo, R.A. (2008): Deleterious action of FA metabolites on ATP synthesis: possible link between lipotoxicity, mitochondrial dysfunction, and insulin resistance. Am. J. Physiol. Endocrinol. Metab., 295, E678-E685.

Aggerbeck, M., Garlatti, M., Feilleux-Duché, S., Veyssier, C., Daheshia, M., Hanoune, J. and Barouki, R. (1993): Regulation of the cytosolic aspartate aminotransferase housekeeping gene promoter by glucocorticoids, cAMP, and insulin. Biochemistry, 32, 9065-9072.

Agress, C.M., Jacobs, H.I., Glassner, H.F., Lederer, M.A., Clark, W.G., Wroblewski, F., Karmen, A. and Ladue, J.S. (1955): Serum transaminase levels in experimental myocardial infarction. Circulation, 11, 711-713.

Altszuler, N., Morrison, A., Gottlieb, B., Bjerknes, C., Rathgeb,
I. and Steele, R. (1974): Alteration by fasting of the effects of methylprednisolone on carbohydrate metabolism in the normal dog. Metabolism, 23, 369-374.

Andrade, R.J., Lucena, M.I. and Rodríguez-Mendizábal, M. (1996): Hepatic injury caused by acarbose. Ann. Intern. Med., 124, 931.

Apostolou, A., Saidt, L. and Brown, W.R. (1976): Effect of overnight fasting of young rats on water consumption, body weight, blood sampling, and blood composition. Lab. Anim. Sci., 26, 959-960.

Asayama, K., Sandhir, R., Sheikh, F.G., Hayashibe, H., Nakane, T. and Singh, I. (1999): Increased peroxisomal fatty acid beta-oxidation and enhanced expression of peroxisome proliferator-activated receptor-alpha in diabetic rat liver. Mol. Cell. Biochem., 194, 227-234.

Aubert, J., Begriche, K., Delannoy, M., Morel, I., Pajaud, J., Ribault, C., Lepage, S., McGill, M.R., Lucas-Clerc, C., Turlin, B., Robin, M.A., Jaeschke, H. and Fromenty, B. (2012): Differences in early acetaminophen hepatotoxicity between obese ob/ $\mathrm{ob}$ and $\mathrm{db} / \mathrm{db}$ mice. J. Pharmacol. Exp. Ther., 342, 676-687.

Balfour, J.A., McTavish, D. and Heel, R.C. (1990): Fenofibrate. A review of its pharmacodynamic and pharmacokinetic properties and therapeutic use in dyslipidaemia. Drugs, 40, 260-290.

Báez-Ruiz, A., Escobar, C., Aguilar-Roblero, R., Vázquez-Martínez, O. and Díaz-Muñoz, M. (2005): Metabolic adaptations of liver mitochondria during restricted feeding schedules. Am. J. Physiol. Gastrointest. Liver Physiol., 289, G1015-G1023.

Barouki, R., Pavé-Preux, M., Bousquet-Lemercier, B., Pol, S., Bouguet, J. and Hanoune, J. (1989): Regulation of cytosolic aspartate aminotransferase mRNAs in the Fao rat hepatoma cell line by dexamethasone, insulin and cyclic AMP. Eur. J. Biochem., 186, 79-85.

Baumber, M.E. and Doonan, S. (1976): A quantitative study of the subcellular distribution of aspartate aminotransferase isozymes in rat liver. Int. J. Biochem., 7, 119-124.

Bell, R.M. and Coleman, R.A. (1980): Enzymes of glycerolipid synthesis in eukaryotes. Annu. Rev. Biochem., 49, 459-487.

Belo, P.S., Romsos, D.R. and Leveille, G.A. (1977): Influence of diet on lactate, alanine and serine turnover and incorporation into glucose in the dog. J. Nutr., 107, 397-403.

Blane, G.F. (1987): Comparative toxicity and safety profile of fenofibrate and other fibric acid derivatives. Am. J. Med., 83 (5B), 26-36.

Bomhard, E.M., Bischoff, H., Loof, I. and Popp, A. (1996): Increase in plasma enzyme activities under conditions of increased gluconeogenesis via carbohydrate depletion in rats (Abstract of Program No. 413 in SOT 1996 Annual Meeting). Fundam. Appl. Toxicol., 30, 413.

Bomhard, E.M. (1996): Toxicology of glucosidase inhibitors. In: Handbook of Experimental Pharmacology: Oral Antidiabetics (Kuhlmann, J. and Puls, W. eds.), pp.557-610, Springer Verlag, Berlin.

Bruss, M.D., Khambatta, C.F., Ruby, M.A., Aggarwal, I. and Hellerstein, M.K. (2010): Calorie restriction increases fatty acid synthesis and whole body fat oxidation rates. Am. J. Physiol. Endocrinol. Metab., 298, E108-E116.

Carrascosa, M., Pascual, F. and Aresti, S. (1997): Acarbose-induced acute severe hepatotoxicity. Lancet, 349, 698-699.

Cases, S., Stone, S.J., Zhou, P., Yen, E., Tow, B., Lardizabal, K.D., Voelker, T. and Farese, R.V. Jr. (2001): Cloning of DGAT2, a second mammalian diacylglycerol acyltransferase, and related family members. J. Biol. Chem., 276, 38870-38876.

Chakrabarty, K. and Leveille, G.A. (1968): Influence of periodici- 
A. Kobayashi et al.

ty of eating on the activity of various enzymes in adipose tissue, liver and muscle of the rat. J. Nutr., 96, 76-82.

Chappell, V.L., Thompson, M.D., Jeschke, M.G., Chung, D.H., Thompson, J.C. and Wolf, S.E. (2003): Effects of incremental starvation on gut mucosa. Dig. Dis. Sci., 48, 765-769.

Chen, L.H., Huang, T.L. and Synder, D.L. (1993): Effects of moderate dietary restriction and age on blood parameters and metabolic enzymes in Lobund-Wistar rats. Arch. Gerontol. Geriatr., 16, 69-80.

Chen, H.C., Stone, S.J., Zhou, P., Buhman, K.K. and Farese, R.V. Jr. (2002): Dissociation of obesity and impaired glucose disposal in mice overexpressing acyl coenzyme A:diacylglycerol acyltransferase 1 in white adipose tissue. Diabetes, 51, 3189-3195.

Chesterman, H., Gopinath, C., Peters, D.H. and Lewis, D.J. (1988): Toxicity study of bezafibrate (3) - Acute and subacute toxicity in the rhesus monkey. Clin. Rep., 22, 49-68.

Chitturi, S. and George, J. (2002): Hepatotoxicity of commonly used drugs: nonsteroidal anti-inflammatory drugs, antihypertensives, antidiabetic agents, anticonvulsants, lipid-lowering agents, psychotropic drugs. Semin. Liver Dis., 22, 169-183.

Clampitt, R.B. and Hart, R.J. (1978): The tissue activities of some diagnostic enzymes in ten mammalian species. J. Comp. Pathol., 88, 607-621.

Coleman, R.A. and Lee, D.P. (2004): Enzymes of triacylglycerol synthesis and their regulation. Prog. Lipid Res., 43, 134-176.

Coniff, R.F., Shapiro, J.A. and Seaton, T.B. (1994): Long-term efficacy and safety of acarbose in the treatment of obese subjects with non-insulin-dependent diabetes mellitus. Arch. Intern. Med., 154, 2442-2448.

Coniff, R.F., Shapiro, J.A., Robbins, D., Kleinfield, R., Seaton, T.B., Beisswenger, P. and McGill, J.B. (1995a): Reduction of glycosylated hemoglobin and postprandial hyperglycemia by acarbose in patients with NIDDM. A placebo-controlled dose-comparison study. Diabetes Care, 18, 817-824.

Coniff, R.F., Shapiro, J.A., Seaton, T.B. and Bray, G.A. (1995b): Multicenter, placebo-controlled trial comparing acarbose (BAY g 5421) with placebo, tolbutamide, and tolbutamide-plus-acarbose in non-insulin-dependent diabetes mellitus. Am. J. Med., 98, 443-451.

Coniff, R.F., Shapiro, J.A., Seaton, T.B., Hoogwerf, B.J. and Hunt, J.A. (1995c): A double-blind placebo-controlled trial evaluating the safety and efficacy of acarbose for the treatment of patients with insulin-requiring type II diabetes. Diabetes Care, 18, 928932.

Cornelius, C.E., Bishop, J., Switzer, J. and Rhode, E.A. (1959): Serum and tissue transaminase activities in domestic animals. Cornell Vet., 49, 116-126.

Croset, M., Rajas, F., Zitoun, C., Hurot, J.M., Montano, S. and Mithieux, G. (2001): Rat small intestine is an insulin-sensitive gluconeogenic organ. Diabetes, 50, 740-746.

Dango, D., Umeta, M., Genet, S., Menon, M., Kebede, T. and Beker, J. (2016): Profiles of Liver Function Tests among Type 2 Diabetic Patients Who are Receiving Different Anti-Diabetic Drugs Attending Tikur Anbessa Specialized Hospitals. J. Pharmacogenomics Pharmacoproteomics, 7, 163.

de Bruijne, J.J., Altszuler, N., Hampshire, J., Visser, T.J. and Hackeng, W.H. (1981): Fat mobilization and plasma hormone levels in fasted dogs. Metabolism, 30, 190-194.

de Bruijne, J.J. and de Koster, P. (1983): Glycogenolysis in the fasting dog. Comp. Biochem. Physiol. B, 75, 553-555.

DeFronzo, R.A. (2004): Pathogenesis of type 2 diabetes mellitus. Med. Clin. North Am., 88, 787-835, ix.
DeRosa, G. and Swick, R.W. (1975): Metabolic implications of the distribution of the alanine aminotransferase isoenzymes. J. Biol. Chem., 250, 7961-7967.

Dhahbi, J.M., Mote, P.L., Wingo, J., Tillman, J.B., Walford, R.L. and Spindler, S.R. (1999): Calories and aging alter gene expression for gluconeogenic, glycolytic, and nitrogen-metabolizing enzymes. Am. J. Physiol., 277, E352-E360.

Doi, Y., Kubo, M., Yonemoto, K., Ninomiya, T., Iwase, M., Tanizaki, Y., Shikata, K., Iida, M. and Kiyohara, Y. (2007): Liver enzymes as a predictor for incident diabetes in a Japanese population: the Hisayama study. Obesity (Silver Spring), 15, 18411850.

Drenick, E.J., Simmons, F. and Murphy, J.F. (1970): Effect on hepatic morphology of treatment of obesity by fasting, reducing diets and small-bowel bypass. N. Engl. J. Med., 282, 829-834.

Edgar, A.D., Tomkiewicz, C., Costet, P., Legendre, C., Aggerbeck, M., Bouguet, J., Staels, B., Guyomard, C., Pineau, T. and Barouki, R. (1998): Fenofibrate modifies transaminase gene expression via a peroxisome proliferator activated receptor $\alpha$-dependent pathway. Toxicol. Lett., 98, 13-23.

Felig, P. (1973): The glucose-alanine cycle. Metabolism, 22, 179207.

Freminet, A. and Leclerc, L. (1980): Effect of fasting on glucose, lactate and alanine turnover in rats and guinea-pigs. Comp. Biochem. Physiol. B Biochem. Mol. Biol., 65, 363-367.

Garber, A.J., Karl, I.E. and Kipnis, D.M. (1976): Alanine and glutamine synthesis and release from skeletal muscle. II. The precursor role of amino acids in alanine and glutamine synthesis. J. Biol. Chem., 251, 836-843.

Gentile, S., Turco, S., Guarino, G., Sasso, F.C. and Torella, R. (1999): Aminotransferase activity and acarbose treatment in patients with type 2 diabetes. Diabetes Care, 22, 1217-1218.

Gerich, J.E. and Nurjhan, N. (1993): Gluconeogenesis in type 2 diabetes. In: New Concepts in the Pathogenesis of NIDDM (Östenson, C.G., Efendic, C. and Vranic, M. eds.), Plenum Press, New York.

Gerson, R.J., MacDonald, J.S., Alberts, A.W., Kornbrust, D.J., Majka, J.A., Stubbs, R.J. and Bokelman, D.L. (1989): Animal safety and toxicology of simvastatin and related hydroxyl-methylglutaryl-coenzyme A reductase inhibitors. Am. J. Med., 87, S28-S38.

Gould, S. and Scott, R.C. (2005): 2-Hydroxypropyl-beta-cyclodextrin (HP-beta-CD): a toxicology review. Food Chem. Toxicol., 43, 1451-1459.

Gubern, G., Imperial, S., Busquets, M. and Cortés, A. (1990): Subcellular distribution of alanine aminotransferase activity in human liver. Biochem. Soc. Trans., 18, 1287-1288.

Guo, X., Li, H., Xu, H., Woo, S., Dong, H., Lu, F., Lange, A.J. and $\mathrm{Wu}, \mathrm{C}$. (2012): Glycolysis in the control of blood glucose homeostasis. Acta Pharm. Sin. B, 2, 358-367.

Habold, C., Foltzer-Jourdainne, C., Le Maho, Y., Lignot, J.H. and Oudart, H. (2005): Intestinal gluconeogenesis and glucose transport according to body fuel availability in rats. J. Physiol., 566, 575-586.

Hagopian, K., Ramsey, J.J. and Weindruch, R. (2003): Caloric restriction increases gluconeogenic and transaminase enzyme activities in mouse liver. Exp. Gerontol., 38, 267-278.

Hao, Y., Samuels, Y., Li, Q., Krokowski, D., Guan, B.J., Wang, C., Jin, Z., Dong, B., Cao, B., Feng, X., Xiang, M., Xu, C., Fink, S., Meropol, N.J., Xu, Y., Conlon, R.A., Markowitz, S., Kinzler, K.W., Velculescu, V.E., Brunengraber, H., Willis, J.E., LaFramboise, T., Hatzoglou, M., Zhang, G.F., Vogelstein, B. 
Specificity of transaminase activities in drug-induced hepatotoxicity

and Wang, Z. (2016): Oncogenic PIK3CA mutations reprogram glutamine metabolism in colorectal cancer. Nat. Commun., 7, 11971.

Herzfeld, A. and Greengard, O. (1971): Aspartate aminotransferase in fat tissues: changes with growth and hormones. Biochim. Biophys. Acta, 237, 88-98.

Hildebrand, R. (1983): Microbiochemical approach to liver cell heterogeneity around terminal hepatic venules. Histochemistry, 78, 539-544.

Hoffmann, W.E., Kramer, J., Main, A.R. and Torres, L. (1989): Clinical enzymology. In: The clinical chemistry of laboratory animals (Loeb, W.F. and Quimby, F.W. eds.), pp.239-242, Elsevier Science Ltd., Amsterdam.

Hollander, P. (1992): Safety profile of acarbose, an alpha-glucosidase inhibitor. Drugs, 44 (Suppl 3), 47-53.

Horie, S., Ishii, H. and Suga, T. (1981): Changes in peroxisomal fatty acid oxidation in the diabetic rat liver. J. Biochem., 90, 16911696.

Horio, Y., Nishida, Y., Sakakibara, R., Inagaki, S., Kamisaki, Y. and Wada, H. (1988a): Induction of cytosolic aspartate aminotransferase by a high-protein diet. Biochem. Int., 16, 579-586.

Horio, Y., Tanaka, T., Taketoshi, M., Uno, T. and Wada, H. (1988b): Rat cytosolic aspartate aminotransferase: regulation of its mRNA and contribution to gluconeogenesis. J. Biochem., 103, 805-808.

Horio, Y., Fukui, H., Taketoshi, M., Tanaka, T. and Wada, H. (1988c): Induction of cytosolic aspartate aminotransferase by glucagon in primary cultured rat hepatocytes. Biochem. Biophys. Res. Commun., 153, 410-416.

Iwamoto, Y., Kashiwagi, A., Yamada, N., Terao, S., Mimori, N., Suzuki, M. and Tachibana, H. (2010): Efficacy and safety of vildagliptin and voglibose in Japanese patients with type 2 diabetes: a 12-week, randomized, double-blind, active-controlled study. Diabetes Obes. Metab., 12, 700-708.

Jadaho, S.B., Yang, R.-Z., Lin, Q., Hu, H., Anania, F.A., Shuldiner, A.R. and Gong, D.-W. (2004): Murine alanine aminotransferase: cDNA cloning, functional expression, and differential gene regulation in mouse fatty liver. Hepatology, 39, 1297-1302.

Jean, C., Rome, S., Mathé, V., Huneau, J.F., Aattouri, N., Fromentin, G., Achagiotis, C.L. and Tomé, D. (2001): Metabolic evidence for adaptation to a high protein diet in rats. J. Nutr., 131, 91-98.

Josekutty, J., Iqbal, J., Iwawaki, T., Kohno, K. and Hussain, M.M. (2013): Microsomal triglyceride transfer protein inhibition induces endoplasmic reticulum stress and increases gene transcription via Ire $1 \alpha /$ cJun to enhance plasma ALT/AST. J. Biol. Chem., 288, 14372-14383.

Kale, V.P., Joshi, G.S., Gohil, P.B. and Jain, M.R. (2009): Effect of fasting duration on clinical pathology results in Wistar rats. Vet. Clin. Pathol., 38, 361-366.

Kamimoto, Y., Horiuchi, S., Tanase, S. and Morino, Y. (1985): Plasma clearance of intravenously injected aspartate aminotransferase isozymes: evidence for preferential uptake by sinusoidal liver cells. Hepatology, 5, 367-375.

Kanwar, G. and Saxena, N. (2018): Study of comparison of liver function tests in diabetic case and nondiabetics controls. Int. J. Adv. Res. (Indore), 6, 66-69.

Karmen, A. (1955): A note on the spectrophotometric assay of glutamic-oxaloacetic transaminase in human blood serum. J. Clin. Invest., 34, 131-133. (Appendix to Karmen A., Wrobleski F., LaDue J., Transaminase activity in human blood. J. Clin. Invest., 34, 126-131.)

Kast, A. and Nishikawa, J. (1981): The effect of fasting on oral acute toxicity of drugs in rats and mice. Lab. Anim., 15, 359-364.

Katchman, B.J. and Zipf, R.E. (1970): Correlation between triglycerides and glutamic-pyruvic transaminase in men on high-fat diets. Clin. Chem., 16, 118-123.

Katsunuma, N., Okada, M. and Katsunuma, T. (1966): Different metabolic roles of transaminase isozymes. In: Pyridoxal catalysis: enzymes and model systems (Snell, E.E. and Braunstein, A.E. eds.), pp.255-268, John Wiley and Sons, New York.

Keller, P. (1981): Enzyme activities in the dog: tissue analyses, plasma values, and intracellular distribution. Am. J. Vet. Res., 42, 575-582.

Kennedy, E.P. (1957): Metabolism of lipides. Annu. Rev. Biochem., 26, 119-148.

Kim, Y.S. (1969): The half-life of alanine aminotransferase and of total soluble protein in livers of normal and glucocorticoid-treated rats. Mol. Pharmacol., 5, 105-108.

Kimura, K., Miyakoshi, N., Yamashita, K., Ohashi, Y., Matsumoto, E., Okada, T., Matsunuma, N. and Masuda, H. (1987): Toxicological studies of pravastatin sodium (II) - Thirteen weeks oral toxicity studies in rats. Jpn. Pharmacol. Ther., 15, 19-44. (in Japanese)

Kobayashi, A., Oshida, S., Yamazaki, Y., Maekawa, T., Kuno, H., Sugai, S., Sakakibara, H. and Shimoi, K. (2010): Relationships between plasma and tissue transaminase activities in rats maintained under different feeding conditions. J. Toxicol. Sci., 35, 639-652.

Kobayashi, A., Yokoyama, H., Kataoka, J., Ishida, T., Kuno, H., Sugai, S., Sakakibara, H. and Shimoi, K. (2011): Effects of spaced feeding on gene expression of hepatic transaminase and gluconeogenic enzymes in rats. J. Toxicol. Sci., 36, 325-337.

Kobayashi, A., Suzuki, Y., Kuno, H., Sugai, S., Sakakibara, H. and Shimoi, K. (2009): Effects of fenofibrate on plasma and hepatic transaminase activities and hepatic transaminase gene expression in rats. J. Toxicol. Sci., 34, 377-387.

Kodama, T., Watanabe, E., Tsubuku, S., Otabe, A., Mochizuki, M., Masuyama, T. and Bernard, B.K. (2008): Studies of the toxicological potential of capsinoids: VII. A 13-week toxicity study of dihydrocapsiate in rats. Int. J. Toxicol., 27 (Suppl 3), 79-100.

Kondo, K., Yamada, N., Suzuki, Y., Toyoda, K., Hashimoto, T., Takahashi, A., Kobayashi, A., Shoda, T., Kuno, H. and Sugai, S. (2012): Enhancement of acetaminophen-induced chronic hepatotoxicity in restricted fed rats: a nonclinical approach to acetaminophen-induced chronic hepatotoxicity in susceptible patients. J. Toxicol. Sci., 37, 911-929.

Kornbrust, D.J., MacDonald, J.S., Peter, C.P., Duchai, D.M., Stubbs, R.J., Germershausen, J.I. and Alberts, A.W. (1989): Toxicity of the HMG-coenzyme A reductase inhibitor, lovastatin, to rabbits. J. Pharmacol. Exp. Ther., 248, 498-505.

Kotler, D.P., Kral, J.G. and Björntorp, P. (1982): Refeeding after a fast in rats: effects on small intestinal enzymes. Am. J. Clin. Nutr., 36, 457-462.

Lam, K.S., Tiu, S.C., Tsang, M.W., Ip, T.P. and Tam, S.C. (1998): Acarbose in NIDDM patients with poor control on conventional oral agents. A 24-week placebo-controlled study. Diabetes Care, 21, 1154-1158.

Lam, T.K., van de Werve, G. and Giacca, A. (2003): Free fatty acids increase basal hepatic glucose production and induce hepatic insulin resistance at different sites. Am. J. Physiol. Endocrinol. Metab., 284, E281-E290.

Lamia, K.A., Storch, K.F. and Weitz, C.J. (2008): Physiological significance of a peripheral tissue circadian clock. Proc. Natl. Acad. Sci. USA, 105, 15172-15177. 
A. Kobayashi et al.

Lardizabal, K.D., Mai, J.T., Wagner, N.W., Wyrick, A., Voelker, T. and Hawkins, D.J. (2001): DGAT2 is a new diacylglycerol acyltransferase gene family: purification, cloning, and expression in insect cells of two polypeptides from Mortierella ramanniana with diacylglycerol acyltransferase activity. J. Biol. Chem., 276, 38862-38869.

Lee, W.M. (2003): Drug-induced hepatotoxicity. N. Engl. J. Med., 349, 474-485.

Lehner, R. and Kuksis, A. (1996): Biosynthesis of triacylglycerols. Prog. Lipid Res., 35, 169-201.

Leung, F.Y. and Henderson, A.R. (1981): Isolation and purification of aspartate aminotransferase isoenzymes from human liver by chromatography and isoelectric focusing. Clin. Chem., 27, 232238.

Leveille, G.A. and Chakrabarty, K. (1968): In vivo and in vitro studies of gluconeogenesis in meal-fed and nibbling rats. J. Nutr., 96, 397-402.

Lindblom, P., Rafter, I., Copley, C., Andersson, U., Hedberg, J.J., Berg, A.L., Samuelsson, A., Hellmold, H., Cotgreave, I. and Glinghammar, B. (2007): Isoforms of alanine aminotransferases in human tissues and serum--differential tissue expression using novel antibodies. Arch. Biochem. Biophys., 466, 66-77.

MacDonald, J.S., Gerson, R.J., Kornbrust, D.J., Kloss, M.W., Prahalada, S., Berry, P.H., Alberts, A.W. and Bokelman, D.L. (1988): Preclinical evaluation of lovastatin. Am. J. Cardiol., 62, $16 \mathrm{~J}-27 \mathrm{~J}$.

Mahendran, Y., Vangipurapu, J., Cederberg, H., Stancáková, A., Pihlajamäki, J., Soininen, P., Kangas, A.J., Paananen, J., Civelek, M., Saleem, N.K., Pajukanta, P., Lusis, A.J., Bonnycastle, L.L., Morken, M.A., Collins, F.S., Mohlke, K.L., Boehnke, M., Ala-Korpela, M., Kuusisto, J. and Laakso, M. (2013): Association of ketone body levels with hyperglycemia and type 2 diabetes in 9,398 Finnish men. Diabetes, 62, 36183626.

Manabe, S., Sudo, S., Yamashita, K., Miyakoshi, N., Matsunuma, N. and Masuda, H. (1989a): Preliminary dose finding study for subacute toxicological study of pravastatin sodium in monkeys. J. Toxicol. Sci., 14 (Suppl 1), 41-55.

Manabe, S., Sudo, S., Yamashita, K., Miyakoshi, N., Matsunuma, N., Tanase, H. and Masuda, H. (1989b): Subacute toxicological study in monkeys treated orally with pravastatin sodium for 5 weeks. J. Toxicol. Sci., 14 (Suppl 1), 57-83.

Martin, G., Ferrier, B., Conjard, A., Martin, M., Nazaret, R., Boghossian, M., Saadé, F., Mancuso, C., Durozard, D. and Baverel, G. (2007): Glutamine gluconeogenesis in the small intestine of $72 \mathrm{~h}$-fasted adult rats is undetectable. Biochem. J., 401, 465-473.

Mathur, S., Mehta, D.K., Kapoor, S. and Yadav, S. (2016): Liver function in type-2 diabetes mellitus patients. Int. J. Sci. Stud., 3, 43-47.

McCommis, K.S., Chen, Z., Fu, X., McDonald, W.G., Colca, J.R., Kletzien, R.F., Burgess, S.C. and Finck, B.N. (2015): Loss of mitochondrial pyruvate carrier 2 in the liver leads to defects in gluconeogenesis and compensation via pyruvate-alanine cycling. Cell Metab., 22, 682-694.

McGill, M.R. (2016): The past and present of serum aminotransferases and the future of liver injury biomarkers. EXCLI J., 15, 817-828.

Nagae, Y., Miyamoto, M. and Miyamoto, H. (1991): Effect of estrogen replacement on liver function in ovariectomized rats. J. Toxicol. Sci., 16, 87-100.

O’Brien, P.J., Slaughter, M.R., Swain, A., Birmingham, J.M.,
Greenhill, R.W., Elcock, F. and Bugelski, P.J. (2000): Repeated acetaminophen dosing in rats: adaptation of hepatic antioxidant system. Hum. Exp. Toxicol., 19, 277-283.

Oelkers, P., Behari, A., Cromley, D., Billheimer, J.T. and Sturley, S.L. (1998): Characterization of two human genes encoding acyl coenzyme A:cholesterol acyltransferase-related enzymes. J. Biol. Chem., 273, 26765-26771.

Palou, A., Remesar, X., Arola, L. and Alemany, M. (1980): Changes in alanine transaminase activity in several organs of the rat induced by a 24-hour fast. Horm. Metab. Res., 12, 505-508.

Papavramidis, T.S., Kaidoglou, K., Grosomanidis, V. Kazamias, P., Anagnostopoulos, T.H., Paramythiotis, D. and Kotzampassi, K. (2009): Short-term fasting-induced jejunal mucosa atrophy in rats -the role of probiotics during refeeding-. Ann. Gastroenterol., 22, 268-274.

Park, H.S., Jang, J.E., Ko, M.S., Woo, S.H., Kim, B.J., Kim, H.S., Park, H.S., Park, I.S., Koh, E.H. and Lee, K.U. (2016): Statins increase mitochondrial and peroxisomal fatty acid oxidation in the liver and prevent non-alcoholic steatohepatitis in mice. Diabetes Metab. J., 40, 376-385.

Peirson, S.N., Butler, J.N., Duffield, G.E., Takher, S., Sharma, P. and Foster, R.G. (2006): Comparison of clock gene expression in SCN, retina, heart, and liver of mice. Biochem. Biophys. Res. Commun., 351, 800-807.

Puchalska, P. and Crawford, P.A. (2017): Multi-dimensional roles of ketone bodies in fuel metabolism, signaling, and therapeutics. Cell Metab., 25, 262-284.

Rafter, I., Gråberg, T., Kotronen, A., Strömmer, L., Mattson, C., Kim, R., Ehrenborg, E., Andersson, H., Yki-Järvinen, H., Schuppe-Koistinen, I., Ekblom, B., Cotgreave, I. and Glinghammar, B. (2012): Isoform-specific alanine aminotransferase measurement can distinguish hepatic from extrahepatic injury in humans. Int. J. Mol. Med., 30, 1241-1249.

Ramaiah, S.K. (2007): A toxicologist guide to the diagnostic interpretation of hepatic biochemical parameters. Food Chem. Toxicol., 45, 1551-1557.

Ramesh, B. and Pugalendi, K.V. (2006): Impact of umbelliferone (7-hydroxycoumarin) on hepatic marker enzymes in streptozotocin diabetic rats. Indian J. Pharmacol., 38, 209-210.

Rej, R. (1978): Aspartate aminotransferase activity and isoenzyme proportions in human liver tissues. Clin. Chem., 24, 1971-1979.

Remesar, X., Arola, L., Palou, A. and Alemany, M. (1980): Effect of 24-hours fast on aspartate transaminase activities in the organs of the rat. Rev. Esp. Fisiol., 36, 147-150.

Remesar, X. and Alemany, M. (1980): Changes-induced in liver and muscle glycogen and glycogen enzymes by 24 -hour fasting in the rat. Horm. Metab. Res., 12, 19-22.

Reuben, A. (2004): Hy's law. Hepatology, 39, 574-578.

Rosen, F., Roberts, N.R. and Nichol, C.A. (1959): Glucocorticosteroids and transaminase activity. I. Increased activity of glutamicpyruvic transaminase in four conditions associated with gluconeogenesis. J. Biol. Chem., 234, 476-480.

Roy, V., Biswas, J. and Saraf, A. (2018): Study of liver functions parameters in diabetic patients from raipur region. IOSR J. Pharm., 8, 18-21.

Rutter, J., Reick, M., Wu, L.C. and McKnight, S.L. (2001): Regulation of clock and NPAS2 DNA binding by the redox state of NAD cofactors. Science, 293, 510-514.

Sameshima, H., Haraguchi, T., Chihaya, Y., Nagata, R., Ohbayashi, S., Mogi, M. and Tsuchiya, T. (1995a): Repeated oral dose toxicity study of fenofibrate in beagle dogs for 52 weeks. Jpn. Pharmacol. Ther., 23, 83-106. (in Japanese) 
Specificity of transaminase activities in drug-induced hepatotoxicity

Sameshima, H., Omori, M., Honda, T., Nomura, M., Nagata, R., Tsuchiya, T. and Ohbayashi, S. (1995b): Repeated oral dose-toxicity study of fenofibrate in rats for 52 weeks. Jpn. Pharmacol. Ther., 23, 37-56. (in Japanese)

Satoh, Y., Kawai, H., Kudo, N., Kawashima, Y. and Mitsumoto, A. (2006): Time-restricted feeding entrains daily rhythms of energy metabolism in mice. Am. J. Physiol. Regul. Integr. Comp. Physiol., 290, R1276-R1283.

Schmidt, E.S. and Schmidt, F.W. (1988): Glutamate dehydrogenase: biochemical and clinical aspects of an interesting enzyme. Clin. Chim. Acta, 173, 43-55.

Schmidt, F.W. and Schmidt, E. (1989): Diagnostic application of mitochondrial enzymes and isoenzymes. Clin. Chim. Acta, 185, 253-263.

Seeman, P. (1972): The membrane actions of anesthetics and tranquilizers. Pharmacol. Rev., 24, 583-655.

Senior, J.R. (2006): How can 'Hy's law' help the clinician? Pharmacoepidemiol. Drug Saf., 15, 235-239.

Shikama, H., Yajima, M. and Ui, M. (1980): Glycogen metabolism in rat liver during transition from the fed to fasted states. Biochim. Biophys. Acta, 631, 278-288.

Singer, I.I., Kawka, D.W., Kazazis, D.M., Alberts, A.W., Chen, J.S., Huff, J.W. and Ness, G.C. (1984): Hydroxymethylglutaryl-coenzyme A reductase-containing hepatocytes are distributed periportally in normal and mevinolin-treated rat livers. Proc. Natl. Acad. Sci. USA, 81, 5556-5560.

Singer, I.I., Scott, S., Kazazis, D.M. and Huff, J.W. (1988): Lovastatin, an inhibitor of cholesterol synthesis, induces hydroxymethylglutaryl-coenzyme A reductase directly on membranes of expanded smooth endoplasmic reticulum in rat hepatocytes. Proc. Natl. Acad. Sci. USA, 85, 5264-5268.

Smith, S.J., Cases, S., Jensen, D.R., Chen, H.C., Sande, E., Tow, B., Sanan, D.A., Raber, J., Eckel, R.H. and Farese, R.V. Jr. (2000): Obesity resistance and multiple mechanisms of triglyceride synthesis in mice lacking Dgat. Nat. Genet., 25, 87-90.

Smith, D.A. and Schmid, E.F. (2006): Drug withdrawals and the lessons within. Curr. Opin. Drug Discov. Devel., 9, 38-46.

Soling, H.C. and Kleineke, J. (1976): Species dependent regulation of hepatic gluconeogenesis in higher animals. In: Gluconeogenesis: Its Regulation in Mammalian Species (Hanson, R.W. and Mehlman, M.A., eds.), pp.369-462, Wiley, New York.

Stokkan, K.A., Yamazaki, S., Tei, H., Sakaki, Y. and Menaker, M. (2001): Entrainment of the circadian clock in the liver by feeding. Science, 291, 490-493.

Suzuki, T., Nagayabu, T., Sato, S., Abe, T., Miyajima, H. and Matsuo, T. (1991): Effect of carbohydrates on oral toxicity of AO-128 in rats. Jpn. Pharmacol. Ther., 19, 13-19. (in Japanese)

Takahashi, T., Matsuura, C., Toyoda, K., Suzuki, Y., Yamada, N., Kobayashi, A., Sugai, S. and Shimoi, K. (2019): Estimation of potential risk of allyl alcohol induced liver injury in diabetic patients using type 2 diabetes spontaneously diabetic Torii-Lepr ${ }^{\mathrm{fa}}$ (SDT fatty) rats. J. Toxicol. Sci., 44, 759-776.

Tarumi, C., Matsunuma, N., Miyakoshi, N., Yamashita, K. and Masuda, H. (1989): Long term oral administration study of pravastatin sodium to beagles for 104 weeks. J. Toxicol. Sci., 14 (Suppl 1), 85-101.

Temple, R. (2001): Hepatotoxicity through the years: Impact on the
FDA, presented 12 February 2001, www.fda.gov/cder/livertox/ Presentations/im1389/sld001.htm.

Thulin, P., Rafter, I., Stockling, K., Tomkiewicz, C., Norjavaara, E., Aggerbeck, M., Hellmold, H., Ehrenborg, E., Andersson, U., Cotgreave, I. and Glinghammar, B. (2008): PPAR $\alpha$ regulates the hepatotoxic biomarker alanine aminotransferase (ALT1) gene expression in human hepatocytes. Toxicol. Appl. Pharmacol., 231, 1-9.

Tolman, K.G. (2000): Defining patient risks from expanded preventive therapies. Am. J. Cardiol., 85 (12A), 15E-19E.

Tolman, K.G. (2002): The liver and lovastatin. Am. J. Cardiol., 89, 1374-1380.

Tolman, K.G., Fonseca, V., Dalpiaz, A. and Tan, M.H. (2007): Spectrum of liver disease in type 2 diabetes and management of patients with diabetes and liver disease. Diabetes Care, 30, 734743.

Tomkiewicz, C., Muzeau, F., Edgar, A.D., Barouki, R. and Aggerbeck, M. (2004): Opposite regulation of the rat and human cytosolic aspartate aminotransferase genes by fibrates. Biochem. Pharmacol., 67, 213-225.

Unger, R.H. (2002): Lipotoxic diseases. Annu. Rev. Med., 53, 319336.

Verdy, M. (1966): BSP retention during total fasting. Metabolism, 15, 769-772.

Walker, J.F. (1989): Simvastatin: the clinical profile. Am. J. Med., 87(Suppl 4), S44-S46.

Watazu, Y., Uji, Y., Okabe, H., Shirahase, Y., Kaneda, N. and Karmen, A. (1993): Proteinase K inactivation of cytosolic aspartate aminotransferase isoenzyme for measurement of human serum mitochondrial aspartate aminotransferase. J. Clin. Lab. Anal., 7, 81-85.

Watford, M. (2005): Is the small intestine a gluconeogenic organ? Nutr. Rev., 63, 356-360.

Wu, G. (1998): Intestinal mucosal amino acid catabolism. J. Nutr., 128, 1249-1252.

Wu, T., Jin, Y., Ni, Y., Zhang, D., Kato, H. and Fu, Z. (2008): Effects of light cues on re-entrainment of the food-dominated peripheral clocks in mammals. Gene, 419, 27-34.

Yang, R.-Z., Park, S., Reagan, W.J., Goldstein, R., Zhong, S., Lawton, M., Rajamohan, F., Qian, K., Liu, L. and Gong, D.-W. (2009): Alanine aminotransferase isoenzymes: molecular cloning and quantitative analysis of tissue expression in rats and serum elevation in liver toxicity. Hepatology, 49, 598-607.

Yokoyama, H., Kobayashi, A., Kondo, K., Oshida, S.I., Takahashi, T., Masuyama, T., Shoda, T. and Sugai, S. (2018): A pharmacologic increase in activity of plasma transaminase derived from small intestine in animals receiving an acyl CoA: diacylglycerol transferase (DGAT) 1 inhibitor. J. Toxicol. Sci., 43, 135-157.

Zhang, L., Chen, Q., Li, L., Kwong, J.S., Jia, P., Zhao, P., Wang, W., Zhou, X., Zhang, M. and Sun, X. (2016): Alpha-glucosidase inhibitors and hepatotoxicity in type 2 diabetes: a systematic review and meta-analysis. Sci. Rep., 6, 32649-32656.

Zimmerman, H.J. (1999): Drug-induced liver disease. In: Hepatotoxicity. The adverse effects of drugs and other chemicals on the liver, $2^{\text {nd }}$ ed., pp.428-433, Lippincott Williams \& Wilkins, Philadelphia. 